\title{
A review on studies of the 1999 Chi-Chi earthquake for resolving the debatable problems in earthquake physics
}

\author{
Jeen-Hwa Wang * \\ Institute of Earth Sciences, Academia Sinica, Taipei City, Taiwan
}

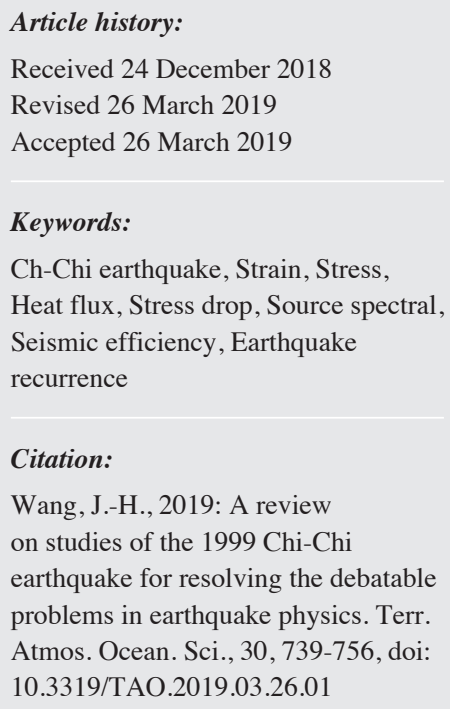

\begin{abstract}
There have been several long-term debatable problems in earthquake physics: (1) the strain problem (localized versus non-localized); (2) the stress problem (high versus low); (3) the heat flux problem (high versus low); (4) the stress drop problem (high versus low); (5) the source spectral problem $\left(\omega^{-2}\right.$ versus $\left.\omega^{-3}\right)$; (6) the seismic efficiency problem (high versus low); and (7) the earthquake recurrence problem (timepredictable versus slip-predictable). The studies of the 20 September $1999 \mathrm{M}_{\mathrm{s}} 7.6$ Chi-Chi, Taiwan, earthquake can be applied to explore these debatable problems.
\end{abstract}

\section{INTRODUCTION}

For a long time, there have been several debatable problems in earthquake physics. Sornette (1999) pointed out three of the problems: (1) the strain problem (localized versus non-localized); (2) the stress problem (high versus low); and (3) the heat flux problem (high versus low). He also named each problem as a "paradox". In addition, there are also four interesting, debatable problems: (1) the stress drop problem (high versus low); (2) the source spectral problem $\left(\omega^{-2}\right.$ versus $\left.\omega^{-3}\right)$; (3) the seismic efficiency problem (high versus low); and (4) the earthquake recurrence problem (time-predictable versus slip-predictable).

On 20 September 1999, the $\mathrm{M}_{\mathrm{s}}$ 7.6 Chi-Chi earthquake ruptured the Chelungpu fault, which is a 100-km-long and east-dipping thrust fault, with a dip angle of $\sim 30^{\circ}$, in central Taiwan (Ma et al. 1999; Shin 2000; Shin and Teng 2001). The epicenter, the surface trace of the fault, and related information are displayed in Fig. 1. From source slip distributions and related information, the Chelungpu fault can be

\footnotetext{
* Corresponding author

E-mail:jhwang@earth.sinica.edu.tw
}

divided into the southern and northern segments, separated almost at a locality near Station TCU065 as displayed in Fig. 1. Hence, in the followings the subscripts ' $S$ ' and ' $N$ ' denote, respectively, the southern and northern segments of the fault.

After the earthquake, the National Science Council (NSC, now the Ministry of Science and Technology), ROC launched a multi-ministry, interdisciplinary science \& technology program (entitled "the Program for Earthquake and Active-Fault Research", abbreviated as the PEAR), with an annual budget of about 5.5 million US dollars, for the earthquake and active fault research during 2000 - 2005 (Wang et al. 2005a). In addition to the NSC, this program was also sponsored by the Central Weather Bureau (CWB), Central Geological Survey (CGS), and Water Resources Agency (WRA). More than fifty principal investigators from several fields participated in the program. During 2000 - 2003, the program focused on the studies of the Chi-Chi earthquake and its aftershocks. From 2004 - 2005, the program was re-formed to be four interdisciplinary projects, including Taiwan Chelungpu Drilling Project (TCDP), Active Fault Study in Southwestern Taiwan (AFST), Seismogenic-zone 
Structures and Seismicity in Taiwan and Surrounding Areas (SSST), and Plate Boundary Observatory in Taiwan (PBOT). This program also attracted international interests in seismological problems of the region. There were two international collaboration projects: the Joint Taiwan-Japan Cooperative Project (JTJCP), whose principal investigator was Prof. M. Ando, Nagoya University, Japan and the Taiwan Geodynamical and Earthquake Research (TAIGER) project, whose principal investigator was Prof. F. T Wu, SUNY-Binghamton, USA.

Based on the PEAR, an island-wide continuouslyrecording GPS network was installed, several down-hole strain-meters were set up, several seismic profiles across the island were imaged, a few shallow and two 2000-m deep boreholes were drilled, and numerous earthquake faults were trenched. Up to date, more than 600 articles were published. This program substantially upgraded the research level of Taiwan. From a NSC's report, the impact factor of earth sciences in Taiwan was the best among the Asian countries during 2001 - 2003. The research results and lesson learned from the earthquake have been widely cited and applied by seismologists and engineers to understand other events and their hazards. In order to comprehensively demonstrate the field surveys and research results made by the earth scientists and earthquake engineers, a book, entitled "The 921 Chi-Chi Great Earthquake", in Chinese was com- piled by Wang et al. (2005b).

The ground motions generated by the earthquake were recorded at more than 900 stations. The stations belong to a network operated by the CWB under the Taiwan Strong Motion Instrumentation Program (TSMIP) (see Liu et al. 1999; Shin and Chang 2005). The network consists of about 1000 stations, each equipped with tri-axial force-balanced accelerometers (Teledyne Geotech A900), with a full scale of $\pm 2 \mathrm{~g}$. The instrument response of the accelerometer is flat with a high-cut filter at $50 \mathrm{~Hz}$, and its recordings are digitized with 16-bit resolution at 200 samples per second. Nine stations (shown by open tringles in Fig. 1) are located much closed to the surface trace of the Chelungpu fault. This could minimize the path effects.

The campaign-surveyed GPS data used in this study were collected from several campaigns mainly conducted by three institutions: the CGS; the Satellite Survey Division (SSD) and Land Survey Bureau (LSB) of the Ministry of Interior (MOI); and the Institute of Earth Sciences, Academia Sinica (IESAS). Also incorporated in the data processing were the continuous GPS data from 41 permanent stations operated by the CWB, MOI, and the IESAS. The pre-earthquake GPS surveys included (1) annual surveys at 22 stations by the IESAS from 1992 - 1999; (2) annual surveys at 49 stations by the CGS from 1998 - 1999; and (3) campaign survey at 40 stations by the SSD, in January

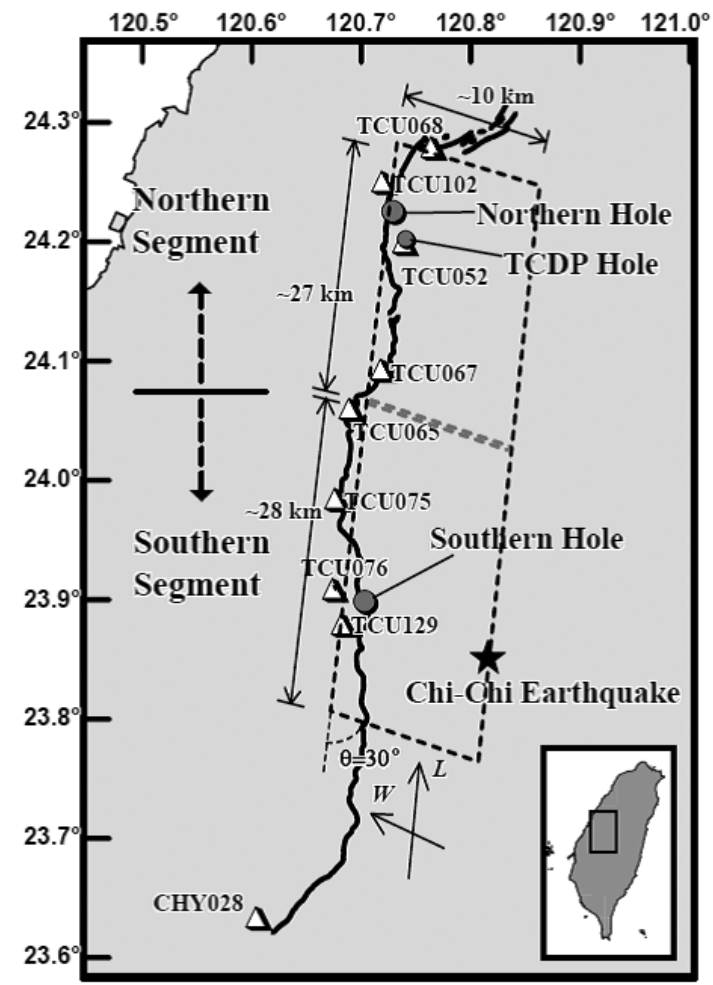

Fig. 1. The epicenter (in a solid star), the Chelungpu fault (in a bold solid line), the sites of nine near-fault accelerographs (in open triangles), the sites of two shallow boreholes (in a larger-sized grey solid circles), and the borehole sites of TCDP (in a smaller-sized grey solid circle). The dashed rectangle denotes the main source area. The double dashed line segments display the boundary of the northern and southern segments of the fault. 
1997. The first post-seismic GPS surveys started two days after the earthquake and were carried out through a joint effort by the IESAS and CGS. Most of the IESAS and CGS stations were surveyed once within the 15-day time period after the mainshock. Subsequently in mid-December 1999, about three months after the earthquake, a more complete GPS campaign was conducted in central Taiwan as a collaborated effort between the LSB and the IESAS. During this survey, 40 LSB stations having better sky visibility as well as all of the CGS and IESAS stations were each occupied once or twice. At two GPS stations near the Chelungpu fault, the horizontal slip rates are $V_{N G P S}=10 \mathrm{~mm} \mathrm{yr}^{-1}$ at Station S016 near the northern segment of the fault and $V_{S G P S}$ $=15.8 \mathrm{~mm} \mathrm{yr}^{-1}$ at Station I007 near the southern segment during the 1992 - 1999 period (Yu et al. 2001, 2003).

In order to study long-term seismicity, it is significant to explore recurrences of large earthquakes rupturing along an active fault. On a certain fault, the average recurrence period of large earthquakes could be several hundred or even a few thousand years. Hence, historical documents and/or paleoseismicity inferred from trenching data are needed to estimate such a recurrence period. Under the PEAR, numerous trenching surveys were made on the Chelungpu fault (Chen et al. 2001a, b, 2004, 2005). The data gained from two trenching sites in the southern segment of the fault, in addition to the 1999 Chi-Chi earthquake, 1 - 4 events rupturing the fault in the past 1900 years were recognized. This will help us to understand the earthquake recurrence along the fault.

Mori et al. (2002) stressed that the data from fault drillings could resolve some significant seismological issues. After the earthquake, several boreholes of different depths were drilled. Through the JTJCP, in 2001 two shallow boreholes cutting across the fault planes, respectively, near the northern and southern segments of the Chelungpu fault were drilled (Huang et al. 2002; Tanaka et al. 2002). The locations are depicted by 'Northern Hole' and 'Southern Hole' with large solid circles in Fig. 1. The northern hole consisted of two linked holes: BH-1 from 0 - $293.4 \mathrm{~m}$ and BH-1A from $208-455.35 \mathrm{~m}$. There was an overlap of $85.4 \mathrm{~m}$ between the two holes. The depth of the southern hole was $211.9 \mathrm{~m}$. The distances from the northern and southern drilling sites to the fault trace are 500 and $250 \mathrm{~m}$, respectively.

In 2005, Taiwan's geoscientists launched the Taiwan Chelungpu-fault Drilling Project (TCDP) to drill two deep holes cutting across the fault plane (Song et al. 2007). The locality of the two holes is shown with a small solid circle in Fig. 1. The two holes, which were located $40 \mathrm{~m}$ apart, were: Hole-A with a depth of $2003.26 \mathrm{~m}$ and Hole-B with a depth of $\sim 1300 \mathrm{~m}$. At least 10 fault zones were recognized in the depth range 1108 - $1857 \mathrm{~m}$ (Hung et al. 2007; Yeh et al. 2007). The shallowest fault zone at depths 1110.37 - 1111.34 $\mathrm{m}$ is considered to be associated with the earthquake and is denoted FZA1111 (Hung et al. 2007). Continuous coring and geophysical well-loggings were made between 431.34 and $2003.26 \mathrm{~m}$ in Hole-A and between 948.42 and $1352.60 \mathrm{~m}$ in Hole-B. In Hole-A, Ma et al. (2006) called a $12-\mathrm{cm}$ thick zone of FZA1111 at depths of $1111.23-1111.35 \mathrm{~m}$ the primary slip zone (PSZ) (see Fig. 2) and named its bottom 2-cm thick sub-zone the major slip zone (MSZ), which is the least deformed and regarded as the slip zone of this earthquake. For the PSZ, Ma et al. (2006) observed that the zone is characterized by bedding-parallel layers of slip zone with a dip angle of $20-30^{\circ}$. Each layer has a thickness of about $2-3 \mathrm{~cm}$, with $\sim 5-\mathrm{mm}$ thick ultrafine grains at the bottom. The degree of fracturing increases from the top of the damaged zone to the gouge zone. Wang et al. (2009) analyzed the seismic velocities, porosity, and permeability of the fault-zone rocks from core samples.

In this study, we will explore the seven problems from the studies of the earthquake based on seismological, geological, and borehole data. Figure 3 is made to describe physical meanings of several source parameters and their relationships used below. In the figure, the bold curve 'ad' represents the nonlinear slip-weakening function of shear stress. The parameter are $D_{c}=$ the characteristic slip displacement of the friction law; $D=$ the final slip, $\sigma_{o}=$ initial stress (or static frictional stress), and $\sigma_{d}=$ dynamic stress. The stress drop is defined as $\Delta \sigma=\sigma_{o}-\sigma_{d}$. Although Fig. 3 is made based on a 1D model, it can exhibit the first-order behavior of an earthquake source and has widely been used by numerous authors (e.g., Kanamori and Heaton 2000; Kanamori and Brodsky 2004; Wang 2019).

\section{THE STRAIN PROBLEM}

The stress problem concerns the debate of localization or non-localization of strain along and surrounding the earthquake fault. Based on the Reid's elastic rebound model (Reid 1910) as shown in Fig. 4, the width, $2 w$, in which the shear strain develops progressively across the fault prior to the earthquake is $2 w=\mu D / \Delta \sigma$ where $\mu$ is the rigidity of faultzone material (Turcotte and Schubert 1982). Since the values of $\Delta \sigma$ for large earthquake are in general $1-10 \mathrm{MPa}$, the estimates of $2 w$ are $5-50 \mathrm{~km}$. Since the model was proposed based on the San Andrea fault, which is a nearly vertical, strike-slip fault, it cannot completely describe the faulting properties of the Chi-Chi earthquake. Nevertheless, it can still give a first-order approach to the fault properties of the Chlungpu fault, because it had a strong strike-slip component along the fault, especially on its northern segment.

Pearson et al. (1995) claimed the existence of strain localization. While, some authors (e.g., Walcott 1978; Shen et al. 1996; Snay et al. 1996) assumed non-localized strain from geodetic displacement profiles obtained across faults which have not yet ruptured in the last decades which give a uniform strain over distances of $150 \mathrm{~km}$ or more from the fault. 


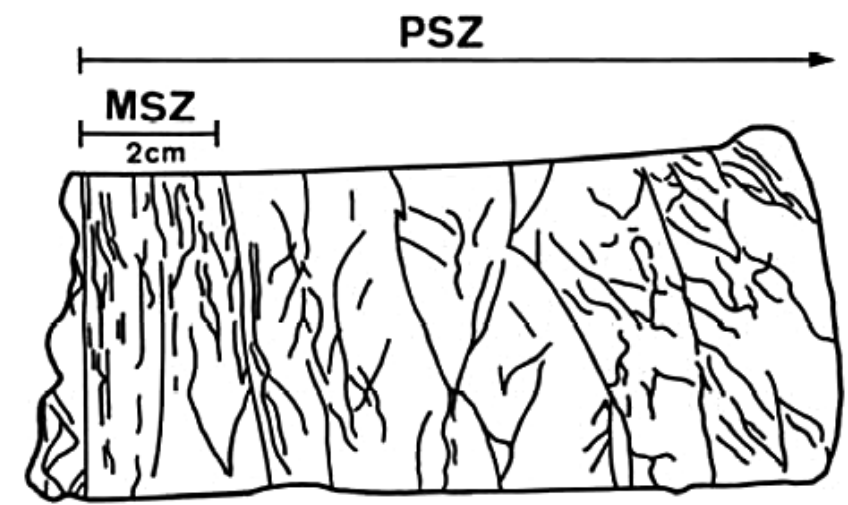

Fig. 2. The traced fractures in 12-cm thick core sample of the Primary Slip Zone (PSZ) drilled from Hole-A. The arrow points to the upward direction. The Major Slip Zone (denoted by MSZ) is at the bottom $2 \mathrm{~cm}$. (This figure is reproduced from Ma et al. 2006.)

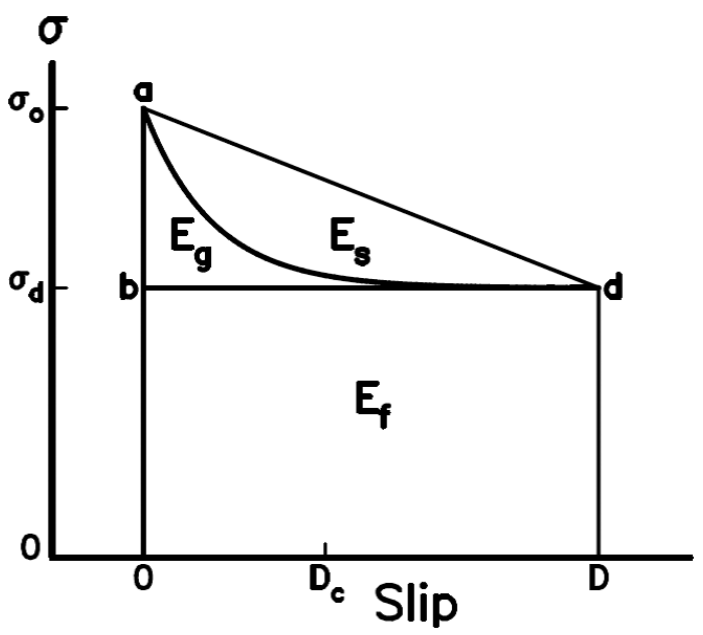

Fig. 3. The curve 'ad' represents the slip-decreasing function of shear stress. The related parameters are: $D_{c}=$ the characteristic slip displacement, $D=$ the final slip, $\sigma_{o}=$ initial stress (or static frictional stress), and $\sigma_{d}=$ dynamic frictional stress. The strain energy, $\Delta E$, is the area of a trapezoid below line 'ad', $E_{s}=$ seismic radiation energy, $E_{g}=$ fracture energy, and $E_{f}=$ frictional energy.
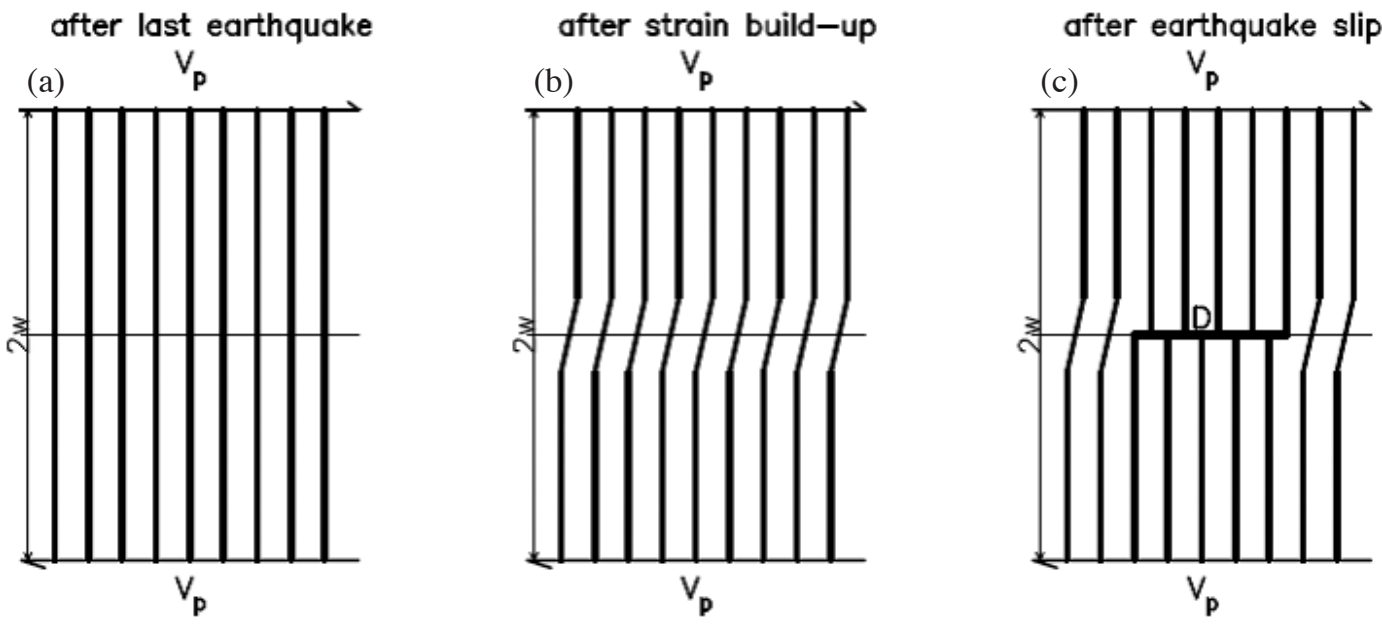

Fig. 4. Reid's elastic rebound model: $V_{p}=$ the speed of plate movement; $2 w=$ the deformed area; $D=$ the final slip. 
For the Chi-Chi earthquake, the estimated value of $D$ $=3.1-6.0 \mathrm{~m}$ (Wang 2006a), $\Delta \sigma=4.2-10.0 \mathrm{MPa}$ (Wang 2005), and $\mu=19 \mathrm{GPa}$ (Wang et al. 2009) lead to $2 w=5.9$ - $27.1 \mathrm{~km}$, with an average of $18 \mathrm{~km}$. This can be confirmed by the field surveys made by Yu et al. (2001, 2003), whose results show that the larger strain is distributed in a range of $\sim 10 \mathrm{~km}$ from the fault. The result clearly suggests strain localization.

\section{THE STRESS PROBLEM}

This problem is that before an earthquake occurs, the fault strength was high or low fault strength. Let $\mu_{f}$ be the static friction coefficient which is defined to be the ratio of shear stress (or static friction stress) over normal pressure on a fault plane. Before an earthquake happen, the fault was locked and thus the static friction stress was just the fault strength on the fault plane. When an earthquake occurs, the static friction stress can decrease due to increases in temperature and fluid pore pressure in the fault zone. In general the fault strength, $\tau$, can be expressed by the relation: $\tau=\tau_{o}+$ $\mu_{f}\left(\sigma_{n}-p\right)$ where $\tau, \tau_{o}, \sigma_{n}$, and $p$ are the effective stress, original stress (or friction strength), normal pressure, and fluid pore pressure, respectively (see Scholz 1990). Clearly, $\tau$ decreases with increasing $p$. In this equation, $\mu_{f}$ is a constant. Nevertheless, there have long been debated about whether $\mu_{f}$ is constant or not during an earthquake.

From laboratory experiments Byerlee (1967) gained $\mu_{f}$ $=0.6 \pm 0.4$ with the maximum value of 0.85 and thus he assumed the existence of high fault strength. This point has been confirmed through stress inversion of small faults slip data in situ by Sibson (1994) who made the in-situ stress measurements from surface to mid-crust through the brittle crust. The results indicate high frictional strengths on the faults. This is in accord with predictions of laboratory friction measurements and Coulomb faulting theory. From the Mohr-Coulomb relation, the lithostatic stress, which is $\sigma_{L}=$ $\rho g H\left(g=9.8 \mathrm{~m} \mathrm{~s}^{-2}\right)$ at a depth of $H$, is $\sim 300 \mathrm{MPa}$ at $H=10 \mathrm{~km}$ and the shear stress is $\sim 200 \mathrm{MPa}$, thus resulting in $\mu_{f} \approx 0.7$.

On the other hand, from tensor analyses, Hickman (1991) obtained $\sigma_{o}=35 \mathrm{MPa}$ for normal faulting, $150 \mathrm{MPa}$ for thrust faults, and $60 \mathrm{MPa}$ for strike-slip faults. This leads to low values of $\sigma_{o} / \sigma_{L}$. From field work, Bird (1989) and Bird and Kong (1994) gained $\mu_{f}=0.17-0.25$ for faults in California. Hence, they proposed low fault strength. Since the friction coefficients estimated from either laboratory measurements or field surveys are usually made after rock sliding or faulting, respectively, their values should be small. Those estimated values could be lower than the original static friction coefficient before rock sliding or faulting. Hence, it is more appropriate to explore the stress problem just during faulting rather than before faulting.

For the Chi-Chi earthquake, Huang et al. (2001) assumed $\sigma_{f} \approx \sigma_{d}$, where $\sigma_{f}$ is the final stress, $\sigma_{d}=E_{f} / A D$, and from $\sigma_{o}=\sigma_{d}+\Delta \sigma_{d}$ they obtained $\Delta \sigma_{d S}=6.5 \mathrm{MPa}, \Delta \sigma_{d N}=$ $30 \mathrm{MPa}, \sigma_{d S}=55 \mathrm{MPa}$, and $\sigma_{d N}=57 \mathrm{MPa}$, thus leading to $\sigma_{o s}$ $=62 \mathrm{MPa}$ and $\sigma_{o N}=87 \mathrm{MPa}$, respectively. Since the average $\sigma_{L}$ at $H=8000 \mathrm{~m}$ on the fault plane is $204 \mathrm{MPa}$, Huang et al. (2001) obtained that $\sigma_{o S}$ and $\sigma_{o N}$ are 52 and $70 \%$ less than $\sigma_{L}$, respectively. Wang (2006b) obtained that $\sigma_{o S}$ and $\sigma_{o N}$ are 31.6 and $44.4 \%$ less than $\sigma_{L}$, respectively. Their results imply that the Chelungpu fault was weaker than the host rocks, and the southern segment was weaker than the northern one.

For two shallow holes drilled after the Chi-Chi earthquake, Mori (2004) obtained $\mu_{f s}=0.7-1.0$ at $H=182 \mathrm{~m}$ and $\mu_{f N}=0.1-0.2$ at $H=320 \mathrm{~m}$. From the spatial distribution of temperature, Tanaka et al. (2007) evaluated the values of $\mu_{f}$ in two slip subzones at the northern hole: 0.13 for the upper subzone and 0.12 for the lower subzone. For two deep holes drilled after the event, Lockner et al. (2005) measured $\mu_{f}$ from the core samples: $0.5-0.7$ in the PSZ at Hole-A (Ma et al. 2006). Sone et al. (2005) inferred a change of $\mu_{f}$ from $1-0.35$ during faulting. Kano et al. (2006) inferred $\mu_{f}=$ 0.08 during faulting. At deep Hole-B, Hirono et al. (2007) inferred that during faulting $\mu_{f}=0.04$ or 0.05 under two different stress conditions. Mizoguchi et al. (2008) gained $\mu_{f}$ $=0.3$ for the black gouge zone (BGZ) and $\mu_{f}=0.5$ for undeformed host rocks. Their results imply that the Chelungpu fault was weak during faulting.

\section{THE HEAT FLUX PROBLEM}

From Fig. 3, the total heat generated during faulting is (Kanamori and Heaton 2000): $E_{f}=\sigma_{d} D A$ where $\sigma_{d}, D$, and $A$ are the dynamic friction stress, average slip, and the area of ruptured plane, respectively. Assume that during the earthquake rupture, heat is distributed within a layer of thickness $h$ around the ruptured plane. Hence, the average temperature rise is $\Delta T=E_{f} / C_{v} \rho A h$ where $C_{v}$ and $\rho$ are, respectively, the specific heat and the density of the fault-zone materials. Define $Q=\Delta T h$ to be the strength of the heat source, we have $Q=\sigma_{d} D / C_{v} \rho$. The value of $\Delta T$ decreases with time in the following equation: $\Delta T=Q / 2(\pi \alpha t)^{1 / 2}$, where $\alpha$ is the heat diffusion coefficient (in $\mathrm{m}^{2} \mathrm{~s}^{-1}$ ).

In a seismically active region, Bullard (1954) proposed that a fault should have high $\mu_{f}$ to allow for large earthquakes, so that it can store a large amount of elastic energy and overpass large barriers. This would yield a high heat flux near the fault. However, if $\mu_{f}$ is high, large earthquakes should generate a large amount of heat by rubbing the two surfaces. This heat would be not easily dissipated in a relatively insulating earth. Under repetition of earthquakes, the heat should accumulate and either result in localized melting (which should inhibit the occurrence of further earthquakes because slow continuous sliding should then occur) or develop a high heat flux at the surface. Hickman (1991) first pointed out the heat flux problem. However, observations made by some authors (e.g., Henyey and Wasserburg 
1971; Lachenbruch and Sass 1980) over the entire state of California have shown the absence of anomalous heat flow across the major faults. Since the earthquakes do not occur frequently in their study areas and their observations were usually conducted for a while after an earthquake or between two events. Hence, their results can only imply a fast decay of heat after an event and cannot indicate whether the heat generation during an earthquake is high or low.

Wang (2006b) first estimated average $\Delta T$ on the fault plane of the Chi-Chi earthquake using $\Delta T=Q / h$ at $t=0$ and

$\Delta T=Q / 2(\pi \alpha t)^{1 / 2}$

at $t=1.82912 \times 10^{8} \mathrm{~s}$ (6 years after the earthquake). His results are: (1) on the northern segment with $Q_{N}=154^{\circ} \mathrm{C}$ $\mathrm{m}$ and $\alpha=1.4 \times 10^{-6} \mathrm{~m}^{2} \mathrm{~s}^{-1}, \Delta T_{N}=154^{\circ} \mathrm{C}$ when $t=0 \mathrm{~s}$ and $\Delta T_{N}=2.67^{\circ} \mathrm{C}$ when $t=1.89216 \times 10^{8} \mathrm{~s}$. When $t=0 \mathrm{~s}$, the temperature rise is $\Delta T_{N}=1100^{\circ} \mathrm{C}$ as $h=0.14 \mathrm{~m}$; and (2) On the southern segment with $Q_{S}=102^{\circ} \mathrm{C}-\mathrm{m}$ and $\alpha=1.4 \times$ $10^{-6} \mathrm{~m}^{2} \mathrm{~s}^{-1}, \Delta T_{N}=102^{\circ} \mathrm{C}$ when $t=0 \mathrm{~s}$ and $\Delta T_{N}=1.77^{\circ} \mathrm{C}$ when $t=1.89216 \times 10^{8} \mathrm{~s}$. When $t=0 \mathrm{~s}$, the temperature rise is $\Delta T_{N}=1100^{\circ} \mathrm{C}$ as $h=0.09 \mathrm{~m}$. The temperature decreased very fast in about $100 \mathrm{~s}$ after it reached its peak value.

From the spatial distribution of $\Delta T$ at $t=1.89216 \times$ $10^{8} \mathrm{~s}$ after the earthquake at a depth of $1111 \mathrm{~m}$ inside HoleA, Kano et al. (2006) obtained $\Delta T=0.053^{\circ} \mathrm{C}$. This gives $Q=1.50^{\circ} \mathrm{C}-\mathrm{m}$ and $\alpha=3.4 \times 10^{-7} \mathrm{~m}^{2} \mathrm{~s}^{-1}$. The values of $\alpha$ measured by Tanaka et al. (2007) from the core samples are $(0.8-2.0) \times 10^{-6} \mathrm{~m}^{2} \mathrm{~s}^{-1}$ in the PSZ and $1.0 \times 10^{-6} \mathrm{~m}^{2} \mathrm{~s}^{-1}$ in the MSZ. From measured $\Delta T$, the estimates of $Q$ at $x=0$, i.e., the initiation point of an earthquake, when $t=4.3625 \times 10^{7}$ $\mathrm{s}(\approx 1.4$ years $)$ are $Q_{N}=3.31^{\circ} \mathrm{C}-\mathrm{m}$ for $\Delta T_{N}(0, t)=0.1^{\circ} \mathrm{C}$ and $\alpha_{N}=2 \times 10^{-6} \mathrm{~m}^{2} \mathrm{~s}^{-1}$ and $Q_{S}=8.28^{\circ} \mathrm{C}-\mathrm{m}$ for $\Delta T_{S}(0, t)=0.5^{\circ} \mathrm{C}$ and $\alpha_{S}=5 \times 10^{-7} \mathrm{~m}^{2} \mathrm{~s}^{-1}$. This leads to $\Delta T_{N}=1100^{\circ} \mathrm{C}$ as $h$ $=0.003 \mathrm{~m}$ and $\Delta T_{S}=1100^{\circ} \mathrm{C}$ as $h=0.0075 \mathrm{~m}$. From these borehole data, Wang (2011) inferred thermal history (see Fig. 5) and the spatial distributions of temperature at several time instants (see Fig. 6) on the Chelungpu fault. Figure 5 shows that the temperature in the heating zone increased to $\sim 1100^{\circ} \mathrm{C}$ in a short span of $2.5 \mathrm{~s}$ and then decayed very fast from the peak. Figure 6 expresses that the temperature was high only in the PSZ and low outside this zone; meanwhile the temperature decreased to $160^{\circ} \mathrm{C}$ in the whole zone 196 $\mathrm{s}$ after the earthquake occurrence. Results suggest that the heat generation was high during the earthquake, but the heat flux is low soon after the event due to a fast decay of heat.

Wang (2011) only considered the thermal effect in his heat conduction model. He took the value of thickness, $h$, of the middle portion of the MSZ recognized by Ma et al. (2006) as shown in Fig. 2 to be the thickness of the heated layer and thus it is a constant. The fluid pore pressure can also affect earthquake ruptures. The combination of thermal effect and fluid pore pressure can produce thermal pressur- ization (Rice 2006; Wang 2006b, 2009a, b) and also discussed by Wang (2011) for the Chi-Chi earthquake. When the exerted total stress, $t$, and fluid pore stress, $p$, are present inside a layer of materials, for examples, a soil or a fault zone, the Terzhagi effective stress, $\tau_{e f f}$, is $\tau$ - $p$ and affected by the thickness of the layer. The Terzhagi effective stress was proposed by Karl von Terzaghi in 1925 (see Skempton 1960). The effective thickness will be larger for larger-size events because the slip duration is longer and heat generation is larger for larger-size events. Inside the fault zone, the combined effect of heat and fluids can lead to the thermal pressurization (Rice 2006). Assuming the 1D slip on a plane and the fluid diffusion in a direction of the $y$ axis that is perpendicular to the fault plane, the temperature change, $\Delta T$, can be written in a form (see Rice 2006).

$\Delta T(y, t)=\left(1 / \rho C_{v}\right) \int \sigma_{f}(\tau) v(\tau) G(t-\tau, y ; \alpha) d \tau$

in which the integration is made from 0 to $\infty ; v(t)=d u(t) /$ $d t ; G(t, y ; \alpha)=H(t) \exp \left(-y^{2} / 4 \alpha t\right) /(4 \pi \alpha t)^{1 / 2}$; and $\sigma_{f}(t)$ and $v(t)$ are the dynamic frictional stress and slip velocity at time $t$, respectively. Considering time-independent slip velocity $v$ $=V_{0}$ and equality between static friction stress and dynamic friction stress, i.e., $\sigma_{f}=\sigma_{d}$, Eq. (2) can be simplified to be the following relation:

$\Delta T(y=0, t)=\left(\sigma_{d} V_{0} / \rho C_{v}\right)(t / \pi \alpha)^{1 / 2}=\sigma_{d} D /\left[\rho C_{v}(\pi \alpha t)^{1 / 2}\right]$

Equation (3) is similar to Eq. (1) except a factor 2. However, Wang (2011) assumed that $\Delta T$ in Eq. (1) is the average value of numerous local values over the heated layer with a thickness $h$. Since $h$ is not an explicit parameter in Eq. (3), its equation is valid only for $h \approx 0$ for Wang's assumption. Actually, the value of $h$ used by Wang (2011) is very small, i.e., $0.003 \mathrm{~m}$. In other words, Eq. (3) is valid only for the events having a very short slip duration. The slip duration is almost the rise time at a point on the source area. Wang (2018b) showed that the rise time increases with a decrease in the characteristic slip distance of a frictional law and an increases in either viscosity or inertia of fault-zone materials. The thickness of heated layer can affect the viscous stress. But, the viscosity remarkably decreases due to a high temperature rise during an earthquake, and thus its effect on slip duration should be weak. Hence, $h$ is a minor factor in influencing the slip duration during faulting. Wang's study (Wang 2011) was based on the borehole data at the depth of $1111 \mathrm{~m}$. The slip duration at this depth should be short, because the rise time is almost shorter than $5 \mathrm{~s}$ at the very shallow parts of the ruptured plane of the earthquake from the inversed results of source ruptures by several authors (e.g., Chi et al. 2001; Lee et al. 2006).

Based on the value of $\Delta T=0.053^{\circ} \mathrm{C}$ measured by 


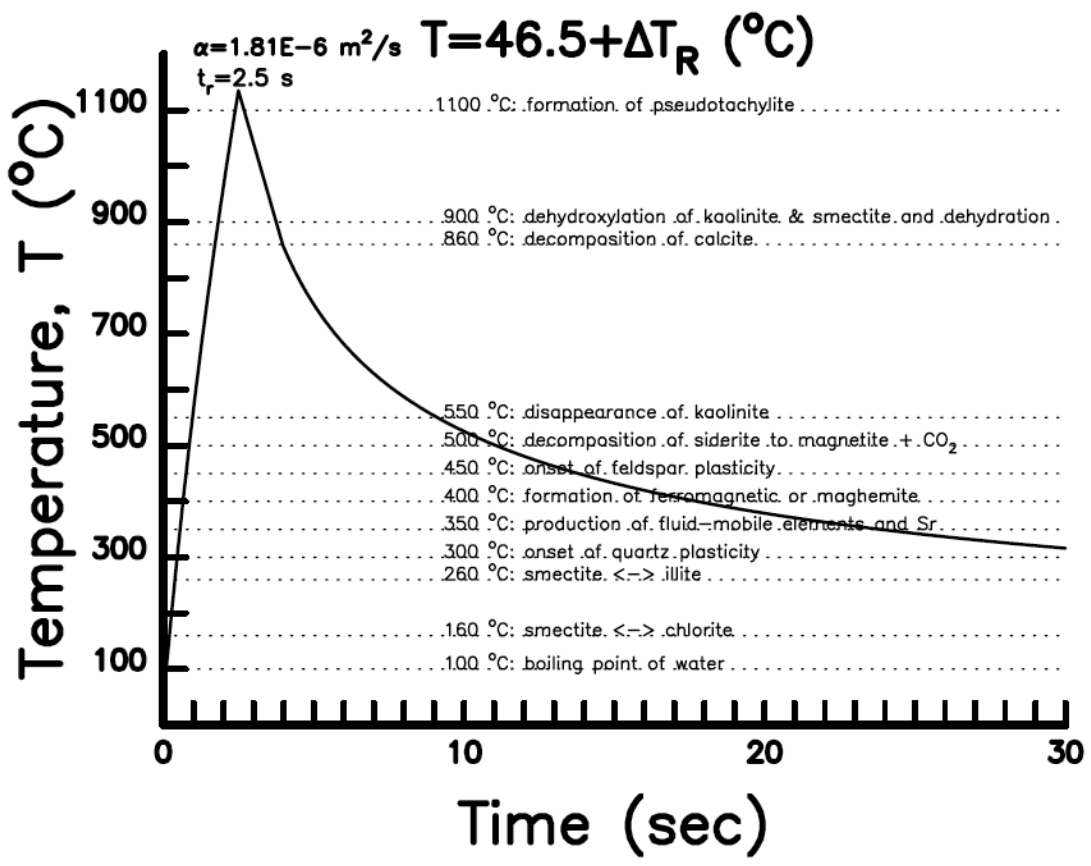

Fig. 5. The thermal history at $x=0$ in the heated layer with $t_{r}=2.5 \mathrm{~s}$ when $Q=7.0^{\circ} \mathrm{C}-\mathrm{m}, \eta=0.005 \mathrm{~m}, \alpha=1.81 \times 10^{-6} \mathrm{~m}^{2} \mathrm{~s}^{-1}$, and $T_{a}=46.5^{\circ} \mathrm{C}$. Several particular temperatures, i.e., $100,160,260,300,450,550,800,950$, and $1100^{\circ} \mathrm{C}$, with related chemical and physical reactions are displayed by the dotted lines (after Wang 2011).

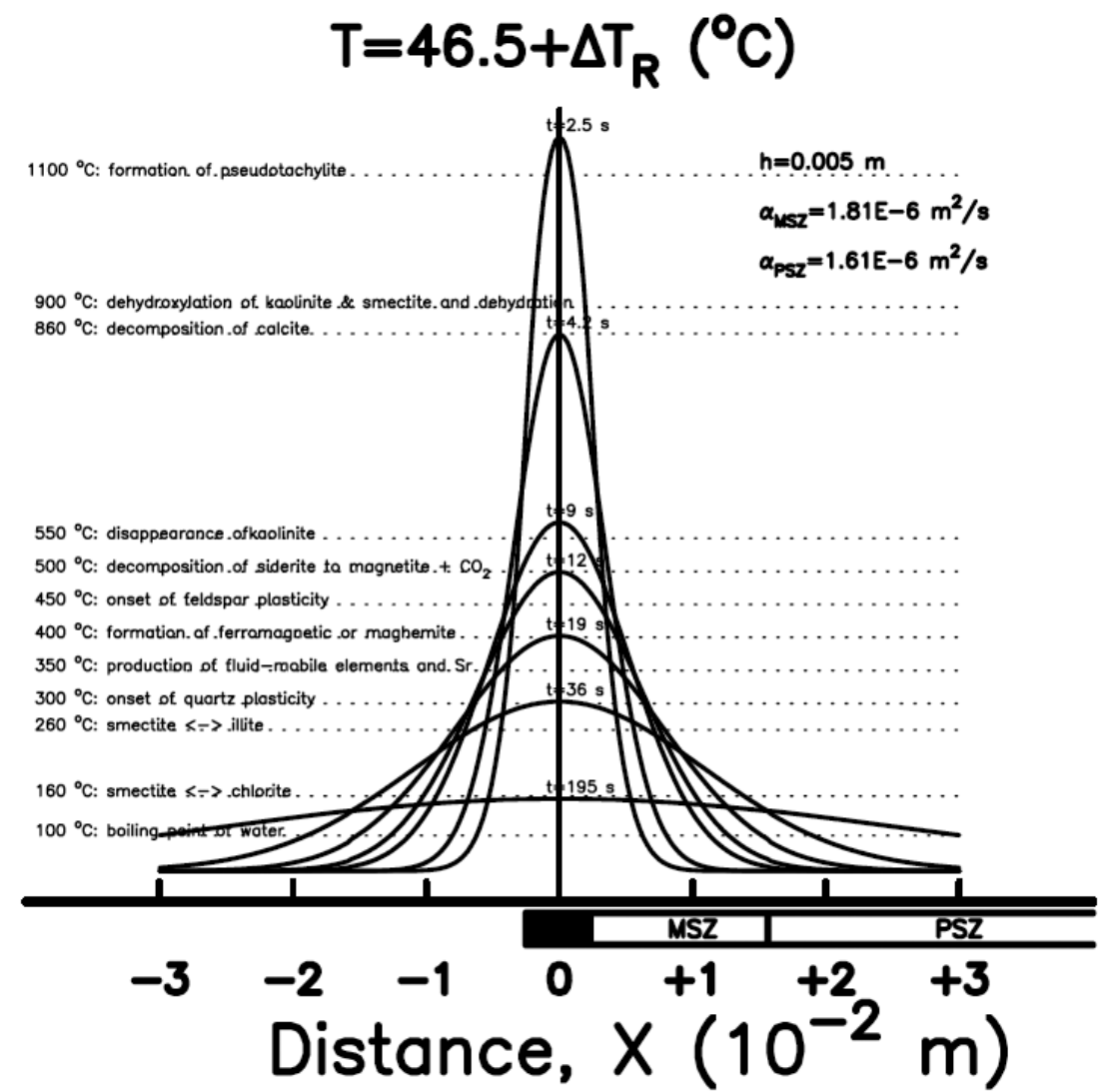

Fig. 6. The spatial distributions of $T\left(=46.5^{\circ}+\Delta T_{R}\right)$, versus distance, $x$, at seven time instants: $t=2.5,4.2,9,12,19,36$, and $195 \mathrm{~s}$ when $Q=7.0^{\circ} \mathrm{C}$ $\mathrm{m}, h=0.005 \mathrm{~m}, \alpha_{M S Z}=1.81 \times 10^{-6} \mathrm{~m}^{2} \mathrm{~s}^{-1}$, and $\alpha_{P S Z}=1.61 \times 10^{-6} \mathrm{~m}^{2} \mathrm{~s}^{-1}$. Several particular temperatures, i.e., 100, 160, 260, 300, 450, 550, 800, 950, and $1100^{\circ} \mathrm{C}$, with related chemical and physical reactions are displayed by the dotted lines. The horizontal open rectangle displays the core sample: the MSZ in the range $-0.0025-0.0175 \mathrm{~m}(2 \mathrm{~cm}$ long $)$ and the PSZ in the range with $x>0.0175 \mathrm{~m}$. The black section in the range $-0.0025-0.0025 \mathrm{~m}$ (i.e., 0 - $0.005 \mathrm{~m}$ in the core) denotes the heated layer (after Wang 2011). 
Kano et al. (2006) in the deep hole at $t=1.89216 \times 10^{8} \mathrm{~s}$ as mentioned above, the heat generation was higher than that estimated by Wang (2011) during the earthquake and the heat flux decayed slower than that evaluated by Wang (2011) after the event. Nevertheless, the heat flux from the two models would both become very low for a while after the earthquake because the factor is only 2 . This means that Wang's conclusion is still acceptable, even though the fluid pore pressure is taken into account.

The temperature elevation on a fault during an earthquake is suppressed significantly if the slip evolution is coupled with slip-induced dilatancy or endothermic dehydration reaction. Taking these factors into account, the analyses by Wang (2011) would overestimate the temperature rise. Nevertheless, his modelled results show that the heat flux decayed very fast soon after the occurrence of the Chi-Chi earthquake. If the temperature rise was lower than his estimate when the slip evolution was coupled with slip-induced dilatancy or endothermic dehydration reaction during the earthquake, the heat flux after the event should be still lower than his estimated value. The inclusion of the two actors would support his results.

\section{THE STRESS DROP PROBLEM}

The stress drop problem includes two issues: the first issue is that after an earthquake happened, there is a total stress drop or a partial stress drop. The second issue is that when an earthquake happens, the stress drop is high or low.

For the first issue, Tsuboi (1956) and Chinnery (1964) assumed the total stress drop, $\Delta \sigma=\sigma_{o}$, i.e., $\sigma_{d}=0$; while Brace and Byerlee (1967) proposed the partial stress drop, i.e., $\Delta \sigma=0.1 \sigma_{o}$. For the Chi-Chi earthquake, the values of $\Delta \sigma_{s}$ and $\Delta \sigma_{s} / \sigma_{o}$ are $4.2 \mathrm{MPa}$ and $5.6 \%$, respectively, by Kikuchi et al. (2000), 10.0 MPa and $13.4 \%$, respectively, by Ma et al. (2006), and 1.21 - 1.64 MPa and 1.6 - 2.2\%, respectively, by Lee et al. (2006). Their results suggest a partial stress drop during the earthquake. As mentioned in section 4 concerning the heat flux, the absolute level of stress (or the fault strength) before and can change after the earthquake due to the effects of heat and fluid pressure. The two effects can reduce $\sigma_{o}$ as well as $\Delta \sigma$. This could be a reason to cause a partial stress drop.

For the second issue, the estimated values of $\Delta \sigma$ from earthquakes are 65 - $89 \mathrm{MPa}$ (for two 1990 Luzon, the Philippines, earthquakes with $m_{b}=5.8$ and 6.0), $190-740 \mathrm{MPa}$ (for the $1968 \mathrm{M}_{\mathrm{s}} 7.9$ Tokachi, Japan, earthquake), and 100 MPa by House and Boatwright (1980), Mori and Shimazaki (1984), and Yomogida and Nakata (1994), respectively. Hence, they assume the high stress drop. On the other hand, Dysart et al. (1988) obtained $\Delta \sigma=0.0008-1.6 \mathrm{MPa}$ for 32 earthquakes with $M=1.6-4.3$ occurred in the Matsushiro region, Japan from July 1971 to September 1976 and thus they proposed the low stress drop. In addition, several au- thors gave diferent observations about $\Delta \sigma$. King and Knopoff (1968) proposed an increase in $\Delta \sigma$ with earthquake magnitude. Baltay et al. (2011) found no dependence of stress drop on moment, investigating many events systematically. Brune et al. (1986) assumed that there are different reasons to cause low and high stress drops. The results inferred by Venkataraman and Kanamori (2004) showed that $\Delta \sigma$ seems to vary with tectonic conditions, thus suggesting the influences of tectonic conditions on earthquakes. However, the latter four groups of researchers did not clearly mention whether $\Delta \sigma$ is high or low during an earthquake, even though their results are important for the studies of stress drops of earthquakes. The stress drop values for small earthquakes can be very high or very low because they can either reflect local complex stress patterns or be made due to high uncertainty of estimates of source areas. Those observations show that the values of $\Delta \sigma$ for large earthquakes are generally in the range of a few MPa to a few tens of MPa. Since the values of $\Delta \sigma$ for large earthquakes are obtained by averaging the local values over a larger source area, they could be stable and constant.

For the Chi-Chi earthquake, the values of static stress drop, $\Delta \sigma$, estimated from teleseismic data are $4.2 \mathrm{MPa}$ by Kikuchi et al. (2000), 10.0 MPa by Ma et al. (2006), and $1.21-1.64 \mathrm{MPa}$ by Lee et al. (2006). From the near-fault seismograms and by using two different methods, Huang et al. (2001) obtained $\Delta \sigma=5.4-39.2 \mathrm{MPa}$ and Hwang et al. (2001) gained $\Delta \sigma=9.4-29.2 \mathrm{MPa}$. In addition, Huang et al. (2001) reported the dynamic stress drop $\Delta \sigma_{d}=6.5 \mathrm{MPa}$ for the southern segment and $\Delta \sigma_{d}=30.0 \mathrm{MPa}$ for the northern one, and Hwang et al. (2001) estimated the values of $\Delta \sigma_{d}$ at three seismic stations: $18.4 \mathrm{MPa}$ at TCU102, 11.7 MPa at TCU076, and 7.9 MPa at TCU129. From their values, the average values of $\Delta \sigma_{d}$ are 11.2 MPa for the southern segment and 20.0 MPa for the northern one. Their results suggest that in comparison with the values of $\Delta \sigma$ obtained by numerous authors (e.g., House and Boatwright 1980; Mori and Shimazaki 1984; Yomogida and Nakata 1994), the ChiChi earthquake had a low stress drop during faulting.

\section{THE SOURCE SPECTRAL PROBLEM}

The detailed description about the physical models of source spectra can be seen in Wang (2019) and only a brief description is given here. The source spectrum, $A(\omega)$, of an earthquake is important for both earthquake physics and seismic hazard assessment. Figure 7 displays the seismogenic zone and ruptured area of an earthquake. In the figure, $L, W$, and $u(x, y, t)$ represent the fault length, fault width, and time-and-space-dependent displacement with a final slip of $D$. A detailed description about the model parameters of a seismogenic zone can be seen in Wang (2018a). The bottom line represents the crustal brittle-ductile transition layer with temperature of $300-450{ }^{\circ} \mathrm{C}$. In the fault zone, the P- and 
$\mathrm{S}$-wave velocities are $v_{p}$ and $v_{s}$, respectively. The source rupture propagates with a velocity of $v_{R}$. Haskell (1966) and Aki (1967) proposed two different models to interpret the source spectra. Haskell (1966) assumed that during the ruptures, the accelerations behave like the Brownian processes in the time and space domain. Hence, his model is

$|A(\omega)|=W D_{0} \mathrm{~L} /\left[1+\left(\omega / \varkappa_{T}\right)^{2}\right]\left\{1+[1-\varpi \cos (\theta)]^{2}\left(\omega / v_{R} \varkappa_{L}\right)^{2}\right\}^{1 / 2}(4)$

where $\theta$ denotes the angle between the direction of slip and the horizontal axis, $\varpi$ is the ratio of $v_{R}$ to $c\left(c=v_{p}\right.$ or $\left.v_{s}\right)$, $\varkappa_{T}$ is the correlation time having a unit of frequency in the time domain, and $\varkappa_{L}$ is the correlation length having a unit of wavenumber in the space domain. On the other hand, Aki (1967) assumed that during the ruptures, the velocities behave like the Brownian processes in the space and time domains. Hence, his model is:

$|A(\omega)|=W D_{o} L /\left[1+\left(\omega / \varkappa_{T}\right)^{2}\right]^{1 / 2}\left\{1+[1-\varpi \cos (\theta)]^{2}\left(\omega / v_{R} \mathcal{\varkappa}_{L}\right)^{2}\right\}^{1 / 2}(5)$

In Eqs. (4) and (5), $\varkappa_{T}$ can be denoted as $\omega_{c}$, i.e., $\omega_{c}$ $=\varkappa_{T}$. The so-called corner frequency is $f_{c}=\omega_{c} / 2 \pi$. Examples of the two models are shown in Fig. 8, where the horizontal axis is represented by the frequency, $f=\omega / 2 \pi$. This figure exhibits three properties for each curve: (1) there is an almost flat curve to represent the more or less constant spectral amplitude at low $f ;(2)$ the curve turns at a turning frequency, $f_{c}$; and (3) there is a line with a slope of -2 for the Fig. $8 \mathrm{a}$ and -3 for Fig. $8 \mathrm{~b}$ to describe the decay of spectral amplitude with increasing frequency. When $f \gg f_{c}$ or

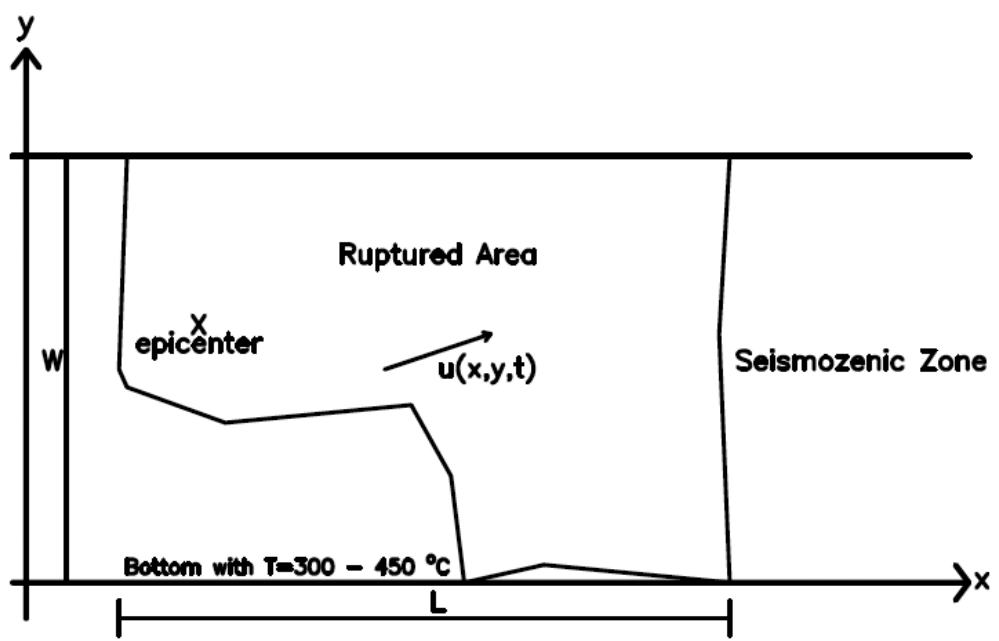

Fig. 7. Seismogenic zone and ruptured area of an earthquake $[L=$ fault length, $W=$ fault width, and $D(x, t)=$ displacement $]$. The bottom line shows the crustal brittle-ductile transition layer with temperatures of $300-400^{\circ} \mathrm{C}$ (modified from Wang 2018a).

(a)

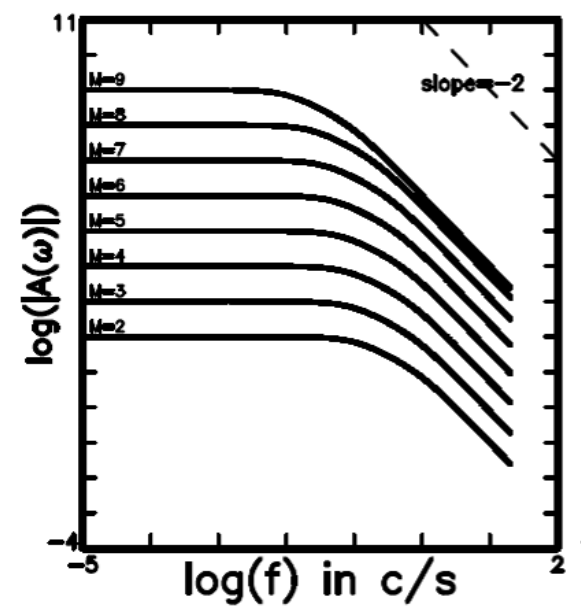

(b) for $\omega$-cube model

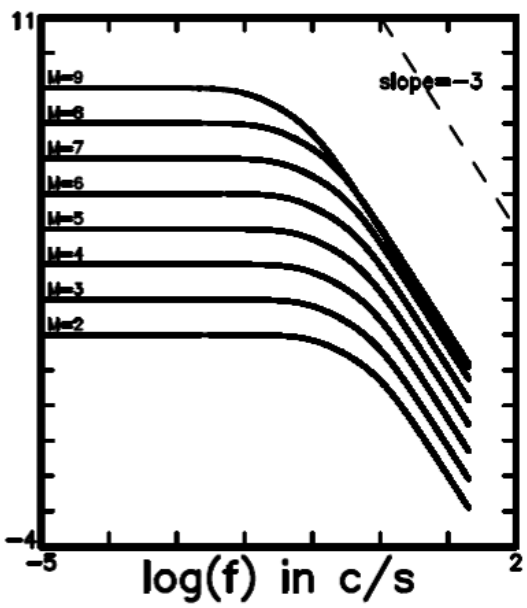

Fig. 8. Theoretical seismic spectra: (a) for the $\omega^{-2}$ model and (b) for the $\omega^{-3}$ model (after Wang 2016). 
$\omega>\omega_{c}$, the approximation of Eq. (4) is $|A(\omega)| \sim \omega^{-3}$, thus leading to the $\omega^{-3}$ model and the approximation of Eq. (5) is $|A(\omega)| \sim \omega^{-2}$, thus giving the $\omega^{-2}$ model.

For a long time, there has been a debate as to whether the $\omega^{-2}$ model or the $\omega^{-3}$ one is better to describe the source spectra of earthquakes (see Wang 2016, 2019; and cited references herein). The debate should be examined relative to the observations retrieved from seismograms. Some authors prefer the $\omega^{-2}$ model (e.g., Ide and Beroza 2001; Imanishi and Ellsworth 2006; Kwiatek et al. 2011; Sivaram et al. 2013; Süle and Wéber 2013; Abercrombie 2015; Denolle and Shearer 2016; Ye et al. 2016); some authors favor the $\omega^{-3}$ one (e.g., Prieto et al. 2004; Mayeda et al. 2005); and some authors (e.g., Uchide and Imanishi 2016) claimed that neither is appropriate to describe the observed source spectra. In addition, from the results by Uchide and Imanishi (2016) it seems that different scaling exponents exist for different types of faulting.

Several reasons could yield the differences between observed source spectra and the theoretical ones. One significant reason is that the frequency-dependent attenuation effect cannot be completely removed from the observations (Anderson and Hough 1984; Anderson 1986; Kim et al. 1997). The $Q$-factor has a general form of $Q(f)=Q_{f} f^{m}$, which can influence the scaling exponent when it cannot be exactly eliminated in the measurements. Kim et al. (1997) suggested a method to separate the attenuation and source effects. Of course, a simple way to separate the attenuation and source effects or to reduce the attenuation effect is the use of near-fault seismograms. Meanwhile, the near-fault seismic station would mainly record the seismic waves generated from a small area, which is almost like a point source, on the fault plane neat it. Since the seismic station is close to the fault zone, the attenuation factor caused by the crustal materials between the source and the station is remarkably reduced and can be ignored. Hence, the spectra can reflect the effect caused by a point-like small source area. Such spectra would be locality-dependent.

The seismograms generated by the Chi-Chi earthquake are recorded at nine near-fault stations (see Fig. 1) for which the distance between a seismic station and the nearest surface trace of the fault is only few to several tens of meters. Huang and Wang (2002) estimated $Q_{s}(f) \sim f^{0.13}$ in the study area, thus showing very weak dependence of $Q_{s}$ on $f$. Hence, the $|A(\omega)|$ in the frequency range of $0.2-3 \mathrm{~Hz}$ cannot be remarkably influenced by wave attenuation. Hence, a change of $|A(\omega)|$ between any two stations is mainly due to the source effect. This provides a chance to explore the scaling laws of seismic source under a weak or ignorable frequencydependent attenuation effect. From the source spectra of S waves recorded at the nine stations (see Fig. 1), Huang and Wang (2002) observed that the pattern of source spectrum at each station is in agreement to the $\omega^{-2}$ model with $f_{c} \approx 0.2$ Hz. Results exhibit that $|A(\omega)|$ has $\omega^{0}$ scaling when $f<0.2$
$\mathrm{Hz}$ and $|A(\omega)| \sim \omega^{-n}$ with the estimated values of $n$ at the nine stations varying from $1.63-3.04$ in the frequency range of $0.2-3 \mathrm{~Hz}$ from south to north: $2.78 \pm 0.03$ at TCU068, 2.91 \pm 0.03 at TCU102, $3.04 \pm 0.03$ at TCU052, $2.23 \pm 0.02$ at TCU067, $2.63 \pm 0.02$ at TCU065, $2.26 \pm 0.03$ at TCU075, $2.08 \pm 0.02$ at TCU076, $1.87 \pm 0.02$ for TCU129, and $1.63 \pm$ 0.02 at $\mathrm{CHY028}$. They assumed that the source effect is the main reason to cause such a variation in ' $n$ ': the $\omega^{-2}$ model for the single-degree-of-freedom rupture processes on the southern fault plane and the $\omega^{-3}$ model for the two-degreeof-freedom ones on the northern fault plane as depicted in Fig. 7, which shows a general picture of source area of the Chi-Chi earthquake inferred by several authors (e.g., Chi et al. 2001; Ji et al. 2001; Ma et al. 2001; Lee et al. 2006). The fault width is shorter on the southern segment than on the northern one.

The results of Huang and Wang (2002) suggest that the two models of source scaling are applicable for earthquakes depending on the rupture processes. In addition, their scaling exponents are also consistent with those proposed by Kaneko and Shearer (2015) who suggested that it could be better to describe source spectra by using the scaling laws having non-integer exponents. In order to gain the scaling laws of source spectra Haskell (1966) assumed standard Brownian motions of accelerations and Aki (1967) proposed standard Brownian motions of velocities on the fault plane. The standard Brownian motions will lead to an integer fractal dimension (cf. Mandelbrot 1977). Hence, from their assumptions, the scaling exponents of spatial distribution of displacements and/or some source parameters on a fault plane should be an integer. When the spatial distribution of displacements on a fault plane are fractals or fractional Brown fractals (see Wang 1995, 1996, 1997), I assume that the scaling exponent is not necessary an integer and then interpret the observations. Of course, this is an interesting problem and needs more studies in near future.

\section{THE SEISMIC EFFICIENCY PROBLEM}

In Fig. 3, the strain energy, $\Delta E$, is displayed by the area of a trapezoid below line 'ad', and $E_{s}, E_{g}$, and $E_{f}$ denote the seismic radiation energy, fracture energy, and frictional energy. The seismic efficiency, $\eta$, is defined to be the ratio of seismic radiation energy, $E_{s}$, to the strained energy, $\Delta E$, released during an earthquake. Savage and Wood (1971) assumed $\eta \leq 0.07$. Scholz (1990) suggested $\eta \approx 0.05$ because the stress drop is about one-tenth the mean stress. Kanamori and Anderson (1975) assumed that $\eta$ must decrease with increasing total stress if the stress drop is constant. For mine blast, Spottiswoode and McGarr (1975) reported $\eta \leq 0.01$ for the mine tremors. Boatwright (1978) reported $\eta=0.08$ for an $\mathrm{M}_{\mathrm{L}} 1.5$ event. Kikuchi (1992) reported $\eta=0.012$ 0.22 for 27 large earthquakes and stated that deep events have a smaller value than shallow ones. Kanamori et al. 
(1998) gave $\eta=0.04$ for the 1994 deep Bolivia earthquake. From laboratory experiments and mining-induced events $(M$ $=-1.9-3.3)$, McGarr $(1994,1999)$ hypothesized $\eta \leq 0.06$ and claimed that this hypothesis holds for both small and large events. However, those authors estimated $\eta$ mainly from seismic data. Wang (2004) assumed that the slip distribution inferred only from seismic data cannot completely reflect the static strain field on the fault plane, which is the basis for measuring $\Delta E$, because the seismograms used for source inversion usually consist only of shorter-period signals. Hence, the above-mentioned estimates of $\eta$ are problematic. His strategy is to estimate $\Delta E$ from the displacements on the fault plane inferred from crustal deformations rather than from seismic data.

For the Chi-Chi earthquake, $E_{s}$ and other source parameters were estimated by several researchers from nearfield or teleseismic seismograms with or without GPS data. Dominguez et al. (2003) inferred the slip distribution on the fault plane of the earthquake from SPOT satellite images plus GPS data. Their results are used for estimating $\Delta E$ in this study. The $\eta$ of the earthquake will be calculated from related data. Wang (2004) estimated the value of $\Delta E$ from the slip distribution inferred by Dominguez et al. (2003) is $3.208 \times 10^{24} \mathrm{ergs}$. Based on this value, the $\eta$ calculated from $E_{s}$, measured from near-field seismograms and from nearfield and teleseismic data are 0.137 and 0.262 , respectively. The two values do not seem to agree with the $\eta \leq 0.06$ hypothesis proposed by McGarr (1994).

\section{THE EARTHQUAKE RECURRENCE PROBLEM}

In a tectonically active region, a fault is exerted by movement of two plates with a speed of $V_{p}$ as displayed in Fig. 4. Assume that $V_{p}$ be applied at a distance $w$ from each side of the fault, the strain is $\varepsilon=V_{p} t / 2 w$, where $t$ is the time. Thus, $2 w$ is the width in which the shear strain develops progressively across the fault prior to the earthquake. The stress, $\sigma_{s}$, is $\sigma_{s}=\sigma_{d}+\mu V_{p} t / 2 w$, where $\sigma_{d}$ and $\mu$ are the dynamic friction stress and the crustal rigidity, respectively. When $\sigma$ is equal to the static friction stress $\sigma_{s}$ at $T_{R}=2 w \Delta \sigma /$ $\mu V_{p}$, where $\Delta \sigma=\sigma_{s}-\sigma_{d}$ is the stress drop, the fault slips. Hence, $T_{R}$ is the inter-event time or the recurrence period of an earthquake sequence.

Shimazaki and Nakata (1980) proposed three simple earthquake recurrence models (see Fig. 9), each with a constantly increasing tectonic stress. In models, the stress is controlled by a critical stress level, $\sigma_{c}$, for failure and a base stress level, $\sigma_{b}$. The three models for earthquake recurrence are: (1) perfectly periodic model; (2) time-predictable model; and (3) slip-predictable model as interpreted simplistically from Reid (1910). The first model is specified with constant $\sigma_{c}$ and $\sigma_{b}$, thus resulting in constant stress drops. From this model, both the occurrence time (denoted as $T_{R}$ ) and slip expected to occur in next earthquake can be pre- dicted from both slip amounts and dates of previous ones. The second model is specified with constant $\sigma_{c}$ and variable $\sigma_{b}$, thus leading to variable stress drops. From this model, the occurrence time of next earthquake can be predicted from the slip that occurred in previous one. The third model is specified with varying $\sigma_{c}$ and constant $\sigma_{b}$, thus producing variable stress drops. From this model, the slip of next earthquake can be predicted from the date of previous one. For the perfect periodic model, the width, $w$, of a fault zone must be constant. In fact, numerous factors, including wear process, plasticity, strain rate etc., can change the value of $w$ and thus influence the type of earthquake occurrence (see Wang 2018b). Wang (2018a) studied the effect of wear process in the fault zone on earthquake recurrence. His results show that strong wear process can result in aperiodic behavior of earthquakes and thus neither the time-predictable model nor the slip-predictable one can describe the temporal variation in cumulative slip of earthquakes.

There is still debate concerning these three models. Applying the models to history of uplift at Muroto Point in response to the Nankaido, Japan, earthquake, the time-predictable model works for post-1707 earthquakes, yet not for pre-1707 ones (Ando 1975). For the Parkfield earthquake sequence, Bakun and McEvilly (1984) proposed different models to describe it and Murray and Segall (2002) stressed that it does not obey the time-predictable model. Satake (2018) showed irregular recurrent earthquakes in Japan. A detailed descript can be found in Wang (2018b).

From the paleo-events reported by Chen et al. (2004) at two trenching sites in the southern segment as displayed with a solid circle in Fig. 1, Wang (2005) examined whether the earthquakes having ruptured the Chelungpu fault can be described by one of the three recurrence models or not. In addition to the 1999 Chi-Chi earthquake (denoted by N-0), Chen et al. (2004) identified three pre-historic events (denoted by $\mathrm{N}-1, \mathrm{~N}-2, \mathrm{~N}-3$ ). The cumulative slip (in meters) versus time (in years) for the four events are plotted in Fig. 10: the thick solid line segments representing the history of observed data by Chen et al. (2004) and the thick dashed line segments displaying the same thing just with a time shift to the left to meet the slip-predictable model. The thin solid and dotted lines display the long-term slip rates for the timeand slip-predictable models, respectively. The minus sign denotes "BP". The values of $T_{R}$ of $\mathrm{N}-0$ and $\mathrm{N}-3$ are two controlling points of the plot. The two parallel lines display the slip rate of $V_{s}=4.97 \mathrm{~mm} \mathrm{yr}^{-1}$, and the upper and lower ones are, respectively, for the slip- and time-predictable models. The values of $T_{R}$ of N-1 and N-2 can be estimated based on each model. From the time-predictable model, the optimum values of $T_{R}$ are about 400 years BP for $\mathrm{N}-1$ and 980 years $\mathrm{BP}$ for $\mathrm{N}-2$. Since the estimated $T_{R}$ of $\mathrm{N}-1$ is within the range of 430 - 150 years BP obtained by Chen et al. (2004) or within that of 500 - 300 years BP inferred by Ota et al. (2001), it is acceptable. Chen et al. (2004) expressed that $\mathrm{N}-2$ might 
(a) perfectly predictable model

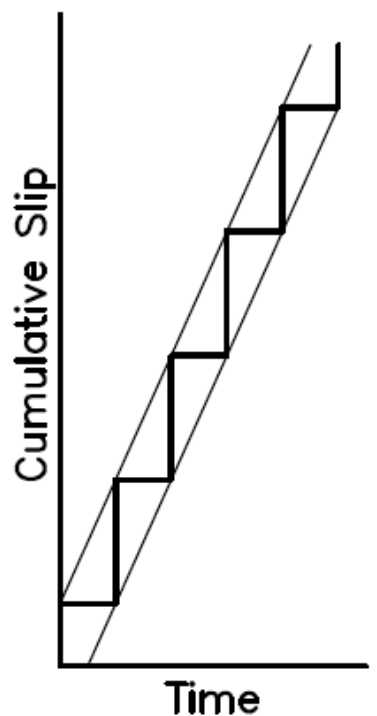

(b) time-predictable model

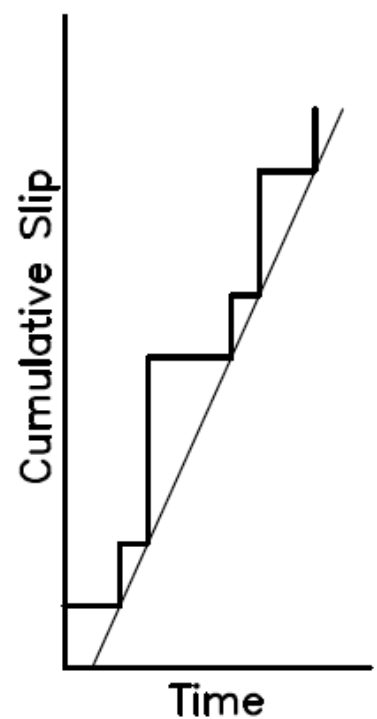

(c) slip-predictable model

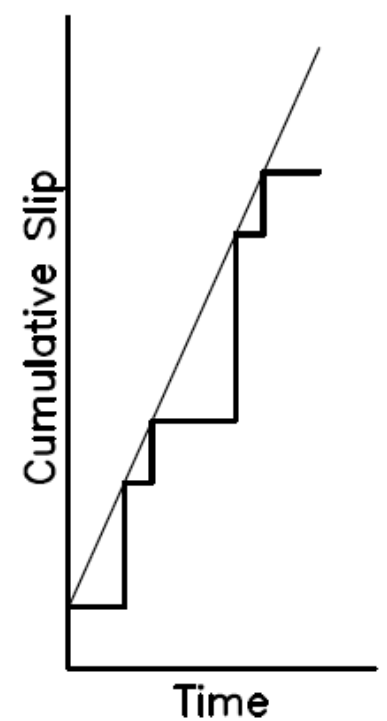

Fig. 9. The earthquake recurrence models (the horizontal axis for time and the vertical axis for cumulative slip): (a) perfectly predictable model; (b) time-predictable model; and (c) slip-predictable model.

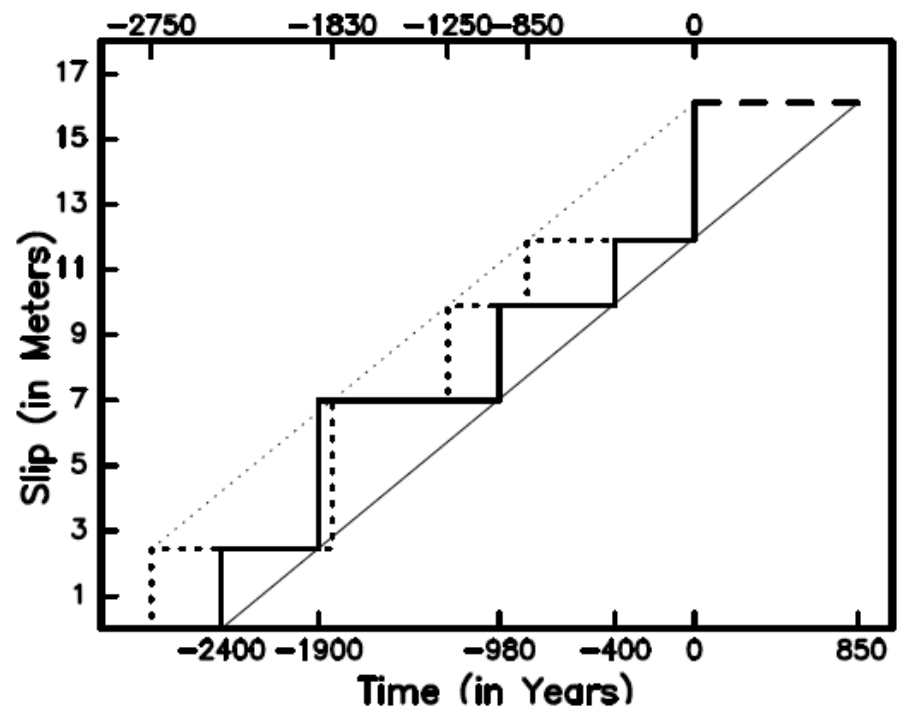

Fig. 10. The plot of cumulative slip versus time: the thick solid line segments representing the history of observed data by Chen et al. (2004) and the thick dashed line segments displaying the same thing just with a time shift to the left to meet the slip-predictable model. The thin solid and dotted lines display the long-term slip rates for the time-predictable model and the slip-predictable one, respectively. The two parallel lines denote a slip rate of $4.97 \mathrm{~mm} \mathrm{yr}^{-1}$. The dashed line denotes the waiting time for an impending earthquake based on the time-predictable model. The number shown along the time axis shows the occurrence time. The minus sign denotes "BP" (after Wang 2005). 
occur in $700-800$ years BP, with a higher uncertainty. The value of 980 years BP seems to be a good one. Hence, the time-predictable model is acceptable. The next earthquake, which would only rupture the southern segment of the fault, will happen 850 years in the future. The study area has been steadily deforming since $0.7 \mathrm{Ma}$. About $30 \%$ strains caused by regional tectonic loading were released during failures of the Chelungpu fault. From the paleo-seismic data obtained from more trenching sites, Chen et al. (2005) also assumed the existence of time-predictable earthquake recurrence along the Chelungpu fault.

Based on a one-body model, with the surface displacements estimated at several near-fault sites, Wang (2003) proposed that the recurrence period of the northern segment of the fault is about 3 times longer than that of the southern one. But, he could not evaluate the definite recurrence period from the model.

\section{CONCLUSIONS}

From the results of geological, geophysical, and seismological studies of the 20 September $1999 \mathrm{M}_{\mathrm{s}}$ 7.6 Chi-Chi, Taiwan, earthquake, we can obtain the following conclusions for the debatable problems: (1) the strain is localized in a range of about $18 \mathrm{~km}$ around the fault; (2) the stress is low within the fault zone during faulting; (3) the heat flux is low along the fault after the earthquake; (4) the stress drop is low and the stress partially drops; (5) the $\omega^{-2}$ and $\omega^{-3}$ source spectral models both hold for different source conditions (the $\omega^{-2}$ model for the single-degree-of-freedom rupture processes and the $\omega^{-3}$ model for the two-degree-of-freedom ones); (6) the seismic efficiency is higher than 0.06 which is the upper bound of $\eta$ hypothesized by McGarr $(1994,1999)$; and (7) the earthquake recurrence is time-predictable.

Acknowledgements This review paper is dedicated to the people who were killed or injured and those who lost their houses and properties during the 1999 Chi-Chi earthquake. Their sacrifices have helped the geoscientists to deeply understand the earthquake. I would like to express my deep thanks to three anonymous reviewers and Prof. Ruey-Juin Rau, Editor of Terrestrial, Atmospheric and Oceanic Sciences, for their valuable comments and suggestions to help me to substantially improve this review article. This study was financially supported by Academia Sinica, the Central Weather Bureau (Grand No.: MOTC-CWB-107-E-02), and the Ministry of Science and Technology (Grand No.: MOST-106-2116-M-001-005), ROC.

\section{REFERENCES}

Abercrombie, R. E., 2015: Investigating uncertainties in empirical Green's function analysis of earthquake source parameters. J. Geophys. Res., 120, 4263-4277, doi: 10.1002/2015JB011984. [Link]

Aki, K., 1967: Scaling law of seismic spectrum. J. Geophys. Res., 72, 1217-1231, doi: 10.1029/jz072i004p01217. [Link]

Anderson, J. G., 1986: Implication of attenuation for studies of the earthquake source. In: Das, S., J. Boatwright, and C. H. Scholz (Eds.), Earthquake Source Mechanics, Volume 37, American Geophysical Union, 311318, doi; 10.1029/GM037p0311. [Link]

Anderson, J. G. and S. E. Hough, 1984: A model for the shape of the Fourier amplitude spectrum of acceleration at high frequencies. Bull. Seismol. Soc. Am., 74, 1969-1993.

Ando, M., 1975: Source mechanisms and tectonic significance of historical earthquakes along the Nankai trough, Japan. Tectonophysics, 27, 119-140, doi: 10.1016/0040-1951(75)90102-x. [Link]

Bakun, W. H. and T. V. McEvilly, 1984: Recurrence models and Parkfield, California, earthquakes. J. Geophys. Res., 89, 3051-3058, doi: 10.1029/JB089iB05p03051. [Link]

Baltay, A., S. Ide, G. Prieto, and G. Beroza, 2011: Variability in earthquake stress drop and apparent stress. Geophys. Res. Lett., 38, L06303, doi: 10.1029/2011GL046698. [Link]

Bird, P., 1989: New finite element techniques for modeling deformation histories of continents with stratified temperature-dependent rheology. J. Geophys. Res., 94, 3967-3990, doi: 10.1029/JB094iB04p03967. [Link]

Bird, P. and X. Kong, 1994: Computer simulations of California tectonics confirm very low strength of major faults. Geol. Soc. Am. Bull., 106, 159-174, doi: 10.1130/0016-7606(1994)106<0159:CSOCTC >2.3. $\mathrm{CO} ; 2$. [Link]

Boatwright, J., 1978: Detailed spectral analysis of two small New York State earthquakes. Bull. Seismol. Soc. Am., 68, 1117-1131.

Brace, W. F. and J. D. Byerlee, 1967: Stick-slip as a mechanism for earthquakes. Science, 153, 990-992, doi: 10.1126/science.153.3739.990. [Link]

Brune, J. N., J. Fletcher, F. Vernon, L. Haar, T. Hanks, and J. Berger, 1986: Low stress-drop earthquakes in the light of new data from the Anza, California telemetered digital array. In: Das, S., J. Boatwright, and C. H. Scholz (Eds.), Earthquake Source Mechanics, Volume 37, American Geophysical Union, 237-245, doi: 10.1029/GM037p0237. [Link]

Bullard, E. C., 1954: The interior of the earth. In: Kuiper, G. P. (Ed.), The Earth as a Planet, Univ. Chicago Press, Chicago, USA, 57-137.

Byerlee, J. D., 1967: Frictional characteristics of granite under high confining pressure. J. Geophys. Res., 72, 3639-3648, doi: 10.1029/JZ072i014p03639. [Link]

Chen, W. S., Y. G. Chen, and H. C. Chang, 2001a: 
Paleoseismic study of the Chelungpu fault in the Mingjian area. West. Pac. Earth Sci., 1, 351-358.

Chen, W. S., Y. G. Chen, H. C. Chang, Y. H. Lee, and J. C. Lee, 2001b: Paleoseismic study of the Chelungpu fault in the Wanfung area. West. Pac. Earth Sci., 1, 499-506.

Chen, W. S., K. J. Lee, L. S. Lee, D. J. Ponti, C. Prentice, Y. G. Chen, H. C. Chang, and Y. H. Lee, 2004: Paleoseismology of the Chelungpu fault during the past 1900 years. Quat. Int., 115-116, 167-176, doi: 10.1016/ s1040-6182(03)00105-8. [Link]

Chen, W. S., K. J.Lee, L. S. Lee, C. N. Yang, S.C. Yang, Y.C. Yen, C. W. Lin, H. C. Huang, W. S. Lin, and T. S. Shih, 2005: Studies of active faults and paleo-earthquakes. In: Wang, J. H., C. Y. Wang, Q. C. Sung, T. C. Shin, S. B. Yu, C. F. Shieh, K. L. Wen, S. L. Chung, M. Lee, K. M. Kuo, K. C. Chang, and S. L. Chung (Eds.), The 921 ChiChi Major Earthquake, Office of Inter-Ministry Science $\&$ Technology Program for Earthquake and Active-fault Research, NSC, 60-82. (in Chinese)

Chi, W. C., D. Dreger, and A. Kaverina, 2001: Finitesource modeling of the 1999 Taiwan (Chi-Chi) earthquake derived from a dense strong-motion network. Bull. Seismol. Soc. Am., 91, 1144-1157, doi: 10.1785/0120000732. [Link]

Chinnery, M. A., 1964: The strength of the Earth's crust under horizontal shear stress. J. Geophys. Res., 69, 20852089, doi: 10.1029/jz069i010p02085. [Link]

Denolle, M. A. and P. M. Shearer, 2016: New perspectives on self-similarity for shallow thrust earthquakes. J. Geophys. Res., 121, 6533-6565, doi: 10.1002/2016JB013105. [Link]

Dominguez, S., J.-P. Avouac, and R. Michel, 2003: Horizontal coseismic deformation of the 1999 Chi-Chi earthquake measured from SPOT satellite images: Implications for the seismic cycle along the western foothills of central Taiwan. J. Geophys. Res., 108, doi: 10.1029/2001JB000951. [Link]

Dysart, P. S., J. A. Snoke, and I. S. Sacks, 1988: Source parameters and scaling relations for small earthquakes in the Matsushiro region, Southwest Honshu, Japan. Bull. Seismol. Soc. Am., 78, 571-589.

Haskell, N. A., 1966: Total energy and energy spectral density of elastic wave radiation from propagating faults. Part II. A statistical source model. Bull. Seismol. Soc. Am., 56, 125-140.

Henyey, T. L. and G. J. Wasserburg, 1971: Heat flow near major strike-slip faults in California. J. Geophys. Res., 76, 7924-7946, doi: 10.1029/jb076i032p07924. [Link]

Hickman, S. H., 1991: Stress in the lithosphere and the strength of active faults. Rev. Geophys., 29, 759-775, doi: 10.1002/rog.1991.29.s2.759. [Link]

Hirono, T., T. Yokoyama, Y. Hamada, W. Tanikawa, T. Mishima, M. Ikehara, V. Famin, M. Tanimizu, W. Lin, W. Soh, and S. R. Song, 2007: A chemical kinetic approach to estimate dynamic shear stress during the 1999 Taiwan Chi-Chi earthquake. Geophys. Res. Lett., 34, L19308, doi: 10.1029/2007GL030743. [Link]

House, L. and J. Boatwright, 1980: Investigation of two high stress drop earthquakes in the Shumagin seismic gap, Alaska. J. Geophys. Res., 85, doi: 10.1029/ jb085ib12p07151. [Link]

Huang, M. W. and J. H. Wang, 2002: Scaling of displacement spectra of near-fault seismograms of the 1999 Chi-Chi, Taiwan, earthquake. Geophys. Res. Lett., 29, 84-1-84-4, doi: 10.1029/2001gl014021. [Link]

Huang, S.-T., J.-C. Wu, J.-H. Hung, and H. Tanaka, 2002: Studies of sedimentary facies, stratigraphy, and deformation structures of the Chelungpu fault zone on cores from drilled wells in Fengyuan and Nantou, central Taiwan. Terr. Atmos. Ocean. Sci., 13, 253-278, doi: 10.3319/TAO.2002.13.3.253(CCE). [Link]

Huang, W. G., J. H. Wang, B. S. Huang, K. C. Chen, T. M. Chang, R. D. Hwang, H. C. Chiu, and C. C. P. Tsai, 2001: Estimates of source parameters for the 1999 Chi-Chi, Taiwan, earthquake based on Brune's source model. Bull. Seismol. Soc. Am., 91, 1190-1198, doi: 10.1785/0120000730. [Link]

Hung, J.-H., Y.-H. Wu, E.-C. Yeh, J.-C. Wu, and TCDP Scientific Party, 2007: Subsurface structure, physical properties, and fault zone characteristics in the scientific drill holes of Taiwan Chelungpu-Fault Drilling Project. Terr. Atmos. Ocean. Sci., 18, 271-293, doi: 10.3319/TAO.2007.18.2.271(TCDP). [Link]

Hwang, R. D., J. H. Wang, B. S. Huang, K. C. Chen, W. G. Huang, T. M. Chang, H. C. Chiu, and C. C. P. Tsai, 2001: Estimates of stress drop of the Chi-Chi, Taiwan, earthquake of 20 September 1999 from near-field seismograms. Bull. Seismol. Soc. Am., 91, 1158-1166, doi: 10.1785/0120000708. [Link]

Ide, S. and G. C. Beroza, 2001: Does apparent stress vary with earthquake size? Geophys. Res. Lett., 28, 33493352, doi: 10.1029/2001GL013106. [Link]

Imanishi, K. and W. L. Ellsworth, 2006: Source scaling relationships of microearthquakes at Parkfield, CA, determined using the SAFOD pilot hole seismic array. In: Abercrombie, R., A. McGarr, G. Di Toro, and H. Kanamori (Eds.), Earthquakes: Radiated Energy and the Physics of Faulting, Volume 170, American Geophysical Union, Washington DC, 81-90, doi: 10.1029/170GM10. [Link]

Ji, C., D. V. Helmberger, T. R. A. Song, K. F. Ma, and D. J. Wald, 2001: Slip distribution and tectonic implication of the 1999 Chi-Chi, Taiwan, earthquake. Geophys. Res. Lett., 28, 4379-4382, doi: 10.1029/2001gl013225. [Link]

Kanamori, H. and D. L. Anderson, 1975: Theoretical basis of some empirical relations in seismology. Bull. Seismol. Soc. Am., 65, 1073-1095. 
Kanamori, H. and E. E. Brodsky, 2004: The physics of earthquakes. Rep. Progr. Phys., 67, 1429-1496, doi: 10.1088/0034-4885/67/8/R03. [Link]

Kanamori, H. and T. H. Heaton, 2000: Microscopic and macroscopic physics of earthquakes. In: Rundle, J. B., D. L. Turcotte, and W. Klein (Eds.), Geocomplexity and the Physics of Earthquakes, Volume 120, American Geophysical Union, Washington D.C., 147-163, doi: 10.1029/GM120p0147. [Link]

Kanamori, H., D. L. Anderson, and T. H. Heaton, 1998: Frictional melting during the rupture of the 1994 Bolivian earthquake. Science, 279, 839-842, doi: 10.1126/ science. 279.5352.839. [Link]

Kaneko, Y. and P. M. Shearer, 2015: Variability of seismic source spectra, estimated stress drop, and radiated energy, derived from cohesive-zone models of symmetrical and asymmetrical circular and elliptical ruptures. J. Geophys. Res., 120, 1053-1079 doi: 10.1002/2014jb011642. [Link]

Kano, Y., J. Mori, R. Fujio, H. Ito, T. Yanagidani, S. Nakao, and K. F. Ma, 2006: Heat signature on the Chelungpu fault associated with the 1999 Chi-Chi, Taiwan earthquake. Geophys. Res. Lett., 33, L14306, doi: 10.1029/2006GL026733. [Link]

Kikuchi, M., 1992: Strain drop and apparent strain for large earthquakes. Tectonophysics, 211, 107-113, doi: 10.1016/0040-1951(92)90054-a. [Link]

Kikuchi, M., Y. Yagi, and Y. Yamanaka, 2000: Source process of the Chi-Chi, Taiwan, earthquake of September 21, 1999 inferred from teleseismic body waves. Bull. Earthquake Res. Inst., Univ. Tokyo, 75, 1-14.

Kim, S. G., Y.-T. Chen, Z.-L. Wu, and G. F. Panza, 1997: A mathematical theorem useful for the direct estimation of seismic source spectra. Bull. Seismol. Soc. Am., 87, 1281-1287.

King, C. Y. and L. Knopoff, 1968: Stress drop in earthquakes. Bull. Seismol. Soc. Am., 58, 249-257.

Kwiatek, G., K. Plenkers, G. Dresen, and JAGUARS Research Group, 2011: Source parameters of picoseismicity recorded at Mponeng deep gold mine, South Africa: Implications for scaling relations. Bull. Seismol. Soc. Am., 101, 2592-2608, doi: 10.1785/0120110094. [Link]

Lachenbruch, A. H. and J. H. Sass, 1980: Heat flow and energetics of the San Andreas fault zone. J. Geophys. Res., 85, 6185-6222, doi: 10.1029/jb085ib11p06185. [Link]

Lee, S. J., K. F. Ma, and H. W. Chen, 2006: Three-dimensional dense strong motion waveform inversion for the rupture process of the 1999 Chi-Chi, Taiwan, earthquake. J. Geophys. Res., 111, B11308, doi: 10.1029/2005JB004097. [Link]

Liu, K. S., T. C. Shin, and Y. B. Tsai, 1999: A free-field strong motion network in Taiwan: TSMIP. Terr.
Atmos. Ocean. Sci., 10, 377-396, doi: 10.3319/ TAO.1999.10.2.377(T). [Link]

Lockner, D. A., C. A. Morrow, S. R. Song, S. Tembe, and T. F. Wong, 2005: Permeability of whole core samples of Chelungpu fault, Taiwan TCDP scientific drillhole. American Geophysical Union, Fall Meeting 2005, abstract id. T43D-04.

Ma, K. F., C. T. Lee, Y. B. Tsai, T. C. Shin, and J. Mori, 1999: The Chi-Chi, Taiwan earthquake: Large surface displacements on an inland thrust fault. Eos, Trans. $A G U$, 80, 605-611, doi: 10.1029/99EO00405. [Link]

Ma, K. F., J. Mori, S. J. Lee, and S. B. Yu, 2001: Spatial and temporal distribution of slip for the 1999 Chi-Chi, Taiwan, earthquake. Bull. Seismol. Soc. Am., 91, 10691087, doi: 10.1785/0120000728. [Link]

Ma, K. F., H. Tanaka, S. R. Song, C. Y. Wang, J. H. Hung, Y. B. Tsai, J. Mori, Y. F. Song, E. C. Yeh, W. Soh, H. Sone, L. W. Kuo, and H. Y. Wu, 2006: Slip zone and energetics of a large earthquake from the Taiwan Chelungpu-fault Drilling Project. Nature, 444, 473476, doi: 10.1038/nature05253. [Link]

Mandelbrot, B. B., 1977: The Fractal Geometry of Nature, W.H. Freeman and Company, New York, 464 pp.

Mayeda, K., R. Gök, W. R. Walter, and A. Hofstetter, 2005: Evidence for non-constant energy/moment scaling from coda-derived source spectra. Geophys. Res. Lett., 32, L10306, doi: 10.1029/2005GL022405. [Link]

McGarr, A., 1994: Some comparisons between mininginduced and laboratory earthquakes. Pure Appl. Geophys., 142, 467-489, doi: 10.1007/bf00876051. [Link]

McGarr, A., 1999: On relating apparent stress to the stress causing earthquake fault slip. J. Geophys. Res., 104, 3003-3011, doi: 10.1029/1998jb900083. [Link]

Mizoguchi, K., M. Takahashi, W. Tanikawa, K. Masuda, S. R. Song, and W. Soh, 2008: Frictional strength of fault gouge in Taiwan Chelungpu fault obtained from TCDP Hole B. Tectonophysics, 460, 198-205, doi: 10.1016/j. tecto.2008.08.009. [Link]

Mori, J., 2004: Energy budget of the 1999 Chichi, Taiwan earthquake. ABSTRACTS Vol. 1, Joint AOGS $1^{\text {st }}$ Annual Meeting \& $2^{\text {nd }}$ APHW Conference, 2004, Singapore, 41.

Mori, J. and K. Shimazaki, 1984: High stress drops of shortperiod subevents from the 1968 Tokachi-Oki earthquake as observed on strong-motion records. Bull. Seismol. Soc. Am., 74, 1529-1544.

Mori, J., H. Ito, and C. Y. Wang, 2002: Chelungpu fault drilling could resolve seismological issues. Eos, Trans. $A G U, \mathbf{8 3}, 255$, doi: 10.1029/2002eo000180. [Link]

Murray, J. and P. Segall, 2002: Testing time-predictable earthquake recurrence by direct measurement of strain accumulation and release. Nature, 419, 287-291, doi: 10.1038/nature00984. [Link]

Ota, Y., C. Huang, P. B. Yuan, Y. Sugiyama, Y. Lee, M. 
Watanabe, H. Sawa, M. Yanagida, S. Sasaki, Y. Suzuki, D. Hirouchi, and K. Taniguchi, 2001: Trenching study at the Tsaotun site in the central part of the Chelungpu fault, Taiwan. West. Pac. Earth Sci., 1, 487498.

Pearson, C. F., J. Beavan, D. J. Darby, G. H. Blick, and R. I. Walcott, 1995: Strain distribution across the Australian-Pacific plate boundary in the central South Island, New Zealand, from 1992 GPS and earlier terrestrial observations. J. Geophys. Res., 100, 22071-22081, doi: 10.1029/95jb02279. [Link]

Prieto, G. A., P. M. Shearer, F. L. Vernon, and D. Kilb, 2004: Earthquake source scaling and self-similarity estimation from stacking P and S spectra. J. Geophys. Res., 109, B08310, doi: 10.1029/2004jb003084. [Link]

Reid, H. F., 1910: The mechanics of the earthquake, the California Earthquake of April 18, 1906. Report of the State Earthquake Investigation Commission in Two Volumes and Atlas, Volume II, Carnegie Institution of Washington, Washington DC.

Rice, J. R., 2006: Heating and weakening of faults during earthquake slip. J. Geophys. Res., 111, B05311, doi: 10.1029/2005JB004006. [Link]

Satake, K., 2018: Geological and historical evidence of irregular recurrent earthquakes in Japan. Phil. Trans. Math. Phys. Eng. Sci., 373, doi: 10.1098/rsta.2014.0375. [Link]

Savage, J. C. and M. D. Wood, 1971: The relation between apparent stress and stress drop. Bull.Seismol.Soc.Am., 61, 1381-1388.

Scholz, C. H., 1990: The Mechanics of Earthquakes and Faulting, Cambridge University Press, New York, 439 pp.

Shen, Z. K., D. D. Jackson, and B. X. Ge, 1996: Crustal deformation across and beyond the Los Angeles basin from geodetic measurements. J. Geophys. Res., 101, 27957-27980, doi: 10.1029/96jb02544. [Link]

Shimazaki, K. and T. Nakata, 1980: Time-predictable recurrence model for large earthquakes. Geophys. Res. Lett., 7, 279-282, doi: 10.1029/g1007i004p00279. [Link]

Shin, T. C., 2000: Some seismological aspects of the 1999 Chi-Chi earthquake in Taiwan.Terr.Atmos.Ocean.Sci., 11, 555-566, doi: 10.3319/TAO.2000.11.3.555(CCE). [Link]

Shin, T. C. and C. H. Chang, 2005: Taiwan's seismic observational system. In: Wang, J. H., C. Y. Wang, Q. C. Sung, T. C. Shin, S. B. Yu, C. F. Shieh, K. L. Wen, S. L. Chung, M. Lee, K. M. Kuo, K. C. Chang, and S. L. Chung (Eds.), The 921 Chi-Chi Major Earthquake, Office of Inter-Ministry Science \& Technology Program for Earthquake and Active-fault Research, NSC, 6082. (in Chinese)

Shin, T. C. and T. L. Teng, 2001: An overview of the 1999 Chi-Chi, Taiwan, earthquake. Bull. Seismol. Soc. Am.,
91, 895-913, doi: 10.1785/0120000738. [Link]

Sibson, R. H., 1994: An assessment of field evidence for 'Byerlee' friction. Pure Appl. Geophys., 142, 645-662, doi: 10.1007/bf00876058. [Link]

Sivaram, K., D. Kumar, S. S. Teotia, S. S. Rai, and K. S. Prakasam, 2013: Source parameters and scaling relations for small earthquakes in Kumaon Himalaya, India. J. Seismol., 17, 579-592, doi: 10.1007/s10950012-9339-y. [Link]

Skempton, A. W., 1960: Significance of Terzaghi's concept of effective stress. In: Bjerrum, L., A. Casagrande, R. B. Peck, A. W. Skempton (Eds.), From Theory to Practice in Soil Mechanics, John Wiley \& Sons, New York.

Snay, R. A., M. W. Cline, C. R. Philipp, D. D. Jackson, Y. Feng, Z. K. Shen, and M. Lisowski, 1996: Crustal velocity field near the big bend of California's San Andreas fault. J. Geophys. Res., 101, 3173-3185, doi: 10.1029/95JB02394. [Link]

Sone, H., T. Shimamoto, H. Noda, S. R. Song, K. F. Ma, J. H. Hung, and C. Y. Wang, 2005: Frictional properties and permeability of fault rocks from Taiwan Chelungpu-fault Drilling Project and their implications for high-velocity slip weakening. AGU Fall Meeting Abstracts, T43D-36, F1825.

Song, S.-R., L.-W. Kuo, E.-C. Yeh, C.-Y. Wang, J.-H. Hung, and K.-F. Ma, 2007: Characteristics of the lithology, fault-related rocks and fault zone structures in TCDP Hole-A. Terr. Atmos. Ocean. Sci., 18, 243-269, doi: 10.3319/TAO.2007.18.2.243(TCDP). [Link]

Sornette, D., 1999: Earthquakes: From chemical alteration to mechanical rupture. Phys. Rep., 313, 237-292, doi: 10.1016/s0370-1573(98)00088-x. [Link]

Spottiswoode, S. M. and A. McGarr, 1975: Source parameters of tremors in a deep-level gold mine. Bull. Seismol. Soc. Am., 65, 93-112.

Süle, B. and Z. Wéber, 2013: Earthquake source parameters and scaling relationships in Hungary (central Pannonian basin). J. Seismol., 17, 507-521, doi: 10.1007/ s10950-012-9334-3. [Link]

Tanaka, H., C. Y. Wang, W. M. Chen, A. Sakaguchi, K. Ujiie, H. Ito, and M. Ando, 2002: Initial science report of shallow drilling penetrating into the Chelungpu fault zone, Taiwan. Terr. Atmos. Ocean. Sci., 13, 227-251, doi: 10.3319/TAO.2002.13.3.227(CCE). [Link]

Tanaka, H., W. M. Chen, K. Kawabata, and N. Urata, 2007: Thermal properties across the Chelungpu fault zone and evaluations of positive thermal anomaly on the slip zones: Are these residuals of heat from faulting? Geophys. Res. Lett., 34, L01309, doi: 10.1029/2006GL028153. [Link]

Tsuboi, C., 1956: Earthquake energy, earthquake volume, aftershock area, and strength of the Earth's crust. $J$. Phys. Earth, 4, 63-66, doi: 10.4294/jpe 1952.4.63. [Link] 
Turcotte, D. L. and G. Schubert, 1982: Geodynamics, Cambridge University Press, New York, 456 pp.

Uchide, T. and K. Imanishi, 2016: Small earthquakes deviate from the omega-square model as revealed by multiple spectral ratio analysis. Bull. Seismol. Soc. Am., 106, 1357-1363, doi: 10.1785/0120150322. [Link]

Venkataraman, A. and H. Kanamori, 2004: Effect of directivity on estimates of radiated seismic energy. J. Geophys. Res., 109, B04301, doi: 10.1029/2003JB002548. [Link]

Walcott, R. I., 1978: Geodetic strains and large earthquakes in the axial tectonic belt of North Island, New Zealand. J. Geophys. Res., 83, 4419-4429, doi: 10.1029/ jb083ib09p04419. [Link]

Wang, J.-H., 1995: Effect of seismic coupling on the scaling of seismicity. Geophys. J. Int., 121, 475-488, doi: 10.1111/j.1365-246x.1995.tb05727.x. [Link]

Wang, J.-H., 1996: Velocity-weakening friction as a factor in controlling the frequency-magnitude relation of earthquakes. Bull. Seismol. Soc. Am., 86, 701-713.

Wang, J.-H., 1997: On the frequency distribution of rupture lengths of earthquakes synthesized from a one-dimensional dynamical lattice model. J. Phys. Earth, 45, 363-381, doi: 10.4294/jpe1952.45.363. [Link]

Wang, J.-H., 2003: A one-body model of the 1999 Chi-Chi, Taiwan, earthquake. Terr. Atmos. Ocean. Sci., 14, 335342, doi: 10.3319/TAO.2003.14.3.335(T). [Link]

Wang, J.-H., 2004: The seismic efficiency of the 1999 Chi-Chi, Taiwan, earthquake. Geophys. Res. Lett., 31, L10613, doi: 10.1029/2004GL019417. [Link]

Wang, J.-H., 2005: Earthquakes rupturing the Chelungpu fault in Taiwan are time predictable. Geophys. Res. Lett., 32, L06316, doi: 10.1029/2004GL021884. [Link]

Wang, J.-H., 2006a: A review of the source parameters of the $1999 \mathrm{M}_{\mathrm{s}} 7.6$ Chi-Chi, Taiwan, earthquake. Terr. Atmos. Ocean. Sci., 17, 179-202, doi: 10.3319/ TAO.2006.17.1.179(T). [Link]

Wang, J.-H., 2006b: Energy release and heat generation during the 1999 Ms7.6 Chi-Chi, Taiwan, earthquake. J. Geophys. Res., 111, B11312, doi: 10.1029/2005JB004018. [Link]

Wang, J.-H., 2009a: Evaluation of the coseismic pore fluid pressure on a thrust fault. Adv. Geosci., 13, 193-202, doi: 10.1142/9789812836182_0013. [Link]

Wang, J.-H., 2009b: Effect of thermal pressurization on radiation efficiency. Bull. Seismol. Soc. Am., 99, 22932304, doi: 10.1785/0120080187. [Link]

Wang, J.-H., 2011: Thermal and pore fluid pressure history on the Chelungpu fault at a depth of $1111 \mathrm{~m}$ during the 1999 Chi-Chi, Taiwan, earthquake. J. Geophys. Res., 116, B03302, doi: 10.1029/2010JB007765. [Link]

Wang, J.-H., 2016: A dynamical study of frictional effect on scaling of earthquake source displacement spectra. Ann. Geophys., 59, S0210, doi: 10.4401/ag-6974.
[Link]

Wang, J.-H., 2018a: A review on scaling of earthquake faults. Terr. Atmos. Ocean. Sci., 29, 589-610, doi: 10.3319/TAO.2018.08.19.01. [Link]

Wang, J.-H., 2018b: A study of earthquake recurrence based on a one-body spring-slider model in the presence of thermal-pressurized slip-weakening friction and viscosity. Nat. Hazards Earth Syst. Sci., 18, 1969-1983, doi: 10.5194/nhess-18-1969-2018. [Link]

Wang, J.-H. 2019: A review on scaling of earthquake source spectra. Surv. Geophys., 40, 133-166, doi: 10.1007/ s10712-019-09512-4. [Link]

Wang, J.-H., C. Y. Wang, Q. C. Sung, T. C. Shin, S. B. Yu, C. F. Shieh, K. L. Wen, S. L. Chung, M. Lee, K. M. Kuo, and K. C. Chang, 2005a: Inter-Ministry Inter-Ministry Science \& Technology Program for Earthquake and Active-fault Research Program for Earthquake and Active-fault Research. In: Wang, J.H., C. Y. Wang, Q. C. Sung, T. C. Shin, S. B. Yu, C. F. Shieh, K. L. Wen, S. L. Chung, M. Lee, K. M. Kuo, K. C. Chang, and S. L. Chung (Eds.), The 921 Chi-Chi Major Earthquake, Office of Inter-Ministry Science \& Technology Program for Earthquake and Active-fault Research, NSC, 60-82. (in Chinese)

Wang, J.-H., C. Y. Wang, Q. C. Song, T. C. Shin, S. B. Yu, C. F. Shieh, K. L. Wen, S. L. Chung, M. Lee, K. M. Kuo, and K. C. Chang, 2005b: The 921 Chi-Chi Major Earthquake, Office of Inter-Ministry Science \& Technology Program for Earthquake and Active-fault Research, National Science Council, 582 pp. (in Chinese)

Wang, J.-H., J.-H. Hung, and J.-J. Dong, 2009: Seismic velocities, density, porosity, and permeability measured at a deep hole penetrating the Chelungpu fault in central Taiwan. J. Asian Earth Sci., 36, 135-145, doi: 10.1016/j.jseaes.2009.01.010. [Link]

Ye, L., T. Lay, H. Kanamori, and L. Rivera, 2016: Rupture characteristics of major and great $\left(M_{w} \geq 7.0\right)$ megathrust earthquakes from 1990 to 2015: 1. Source parameter scaling relationships. J. Geophys. Res., 121, 826844, doi: 10.1002/2015JB012426. [Link]

Yeh, E. C., H. Sone, T. Nakaya, K. H. Ian, S. R. Song, J. H. Hung, W. Lin, T. Hirono, C. Y. Wang, K. F. Ma, W. Soh, and M. Kinoshita, 2007: Core description and characteristics of fault zones from HoleA of the Taiwan Chelungpu-Fault Drilling Project. Terr. Atmos. Ocean. Sci., 18, 327-357, doi: 10.3319/ TAO.2007.18.2.327(TCDP). [Link]

Yomogida, K. and T. Nakata, 1994: Large slip velocity of the surface rupture associated with the 1990 Luzon earthquake. Geophys. Res. Lett., 21, 1799-1802, doi: 10.1029/94g100515. [Link]

Yu, S. B., L.C.Kuo, Y.J.Hsu, H.H.Su, C. C.Liu, C.S.Hou, J. F. Lee, T. C. Lai, C. C. Liu, C. L. Liu, T. F. Tseng, C. S. Tsai, and T. C. Shin, 2001: Preseismic deformation 
and co-seismic displacements associated with the 1999 Chi-Chi, Taiwan, earthquake. Bull. Seismol. Soc. Am., 91, 995-1012, doi: 10.1785/0120000722. [Link]

Yu, S. B., Y. J. Hsu, L. C. Kuo, H. Y. Chen, and C. C.
Liu, 2003: GPS measurement of postseismic deformation following the 1999 Chi-Chi, Taiwan, earthquake. J. Geophys. Res., 108, doi: 10.1029/2003JB002396. [Link] 